مقاله يزوهشى

تأثير پييش تيمار بذر با اسيد ساليسيليك بر شاخصهاى سبز شدن و وزن دانه كَندم رقم :ارسى در شرايط تنش كم آبى بـ (Triticum aestivum)

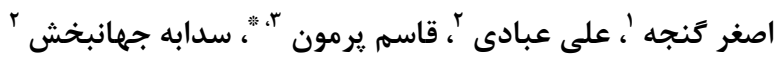

جكيده مبسوط

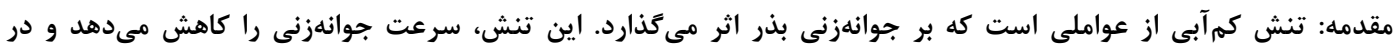

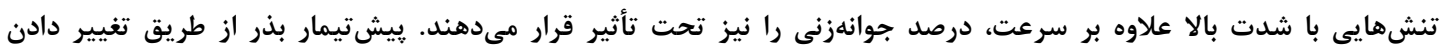

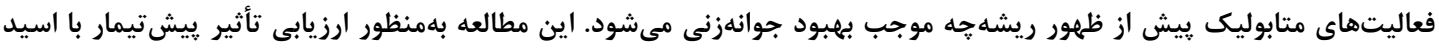

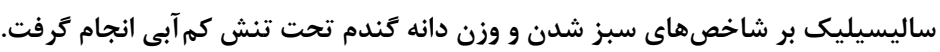

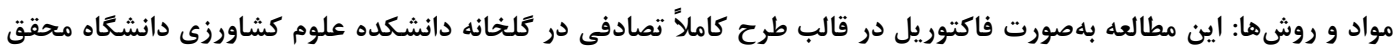

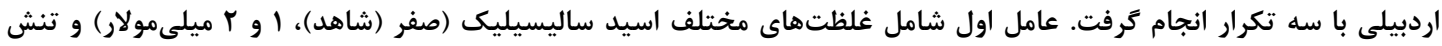

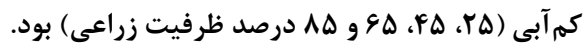

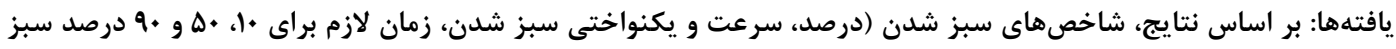

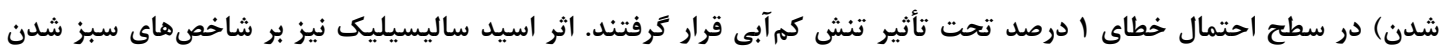

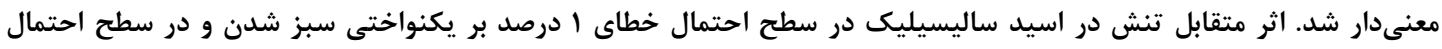

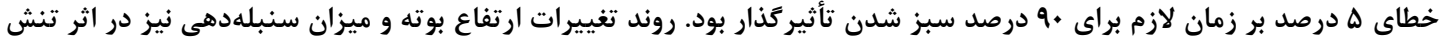

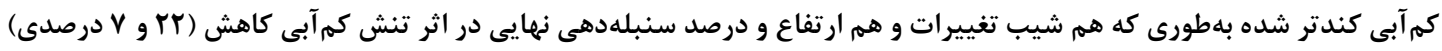

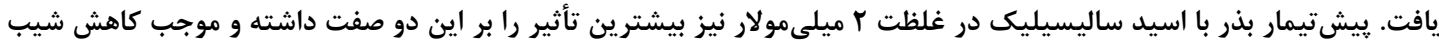

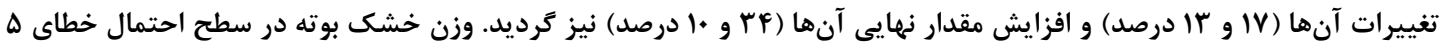

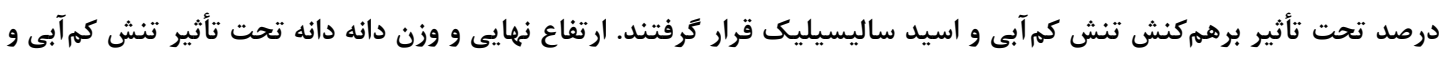

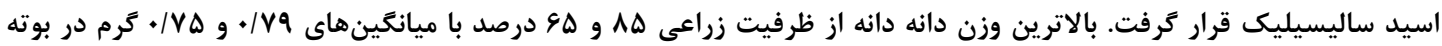

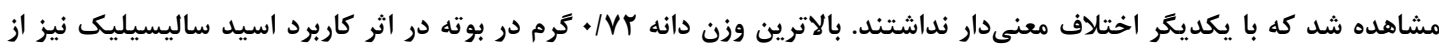

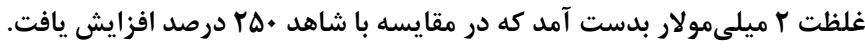

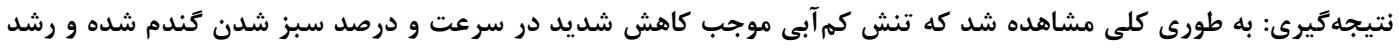

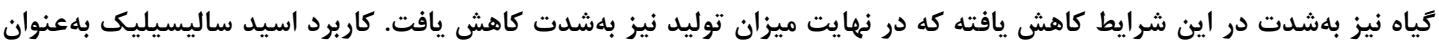

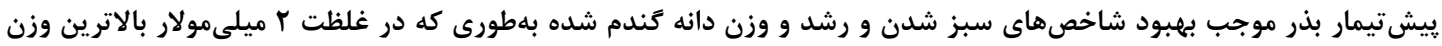

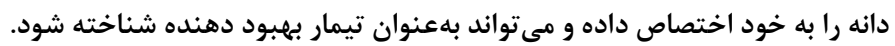
وازههاى كليدى: تنش خشكى، سرعت سبز شدن، كندم، مدل ركرسيونى، هورمون كياهى

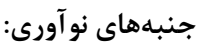

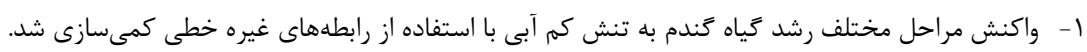

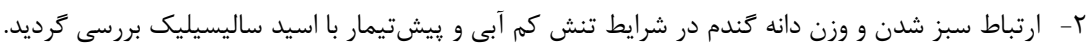

http://dorl.net/dor/20.1001.1.23831251.1399.7.2.3.2

DOI: $10.29252 /$ yujs.7.2.71

CrossMark
' كارشناسى ارشد علفهاى هرز، دانشكده كشاورزى و منابع طبيعى،

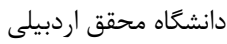
r 'استاد و دانشيار، دانشكده كشاورزى و منابع طبيع طبيعى، دانشكاه محقق اردبيلى " دكترى، دانشكده كشاورزى و منابع طبيعى، دانشعاه محقق اردبيلى

Parmoon@uma.ac.ir رايانامه نويسنده مسئول:" 
بيشتيمار بذر از راهكارهاى پيش از كشت بذر

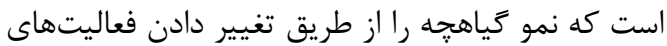

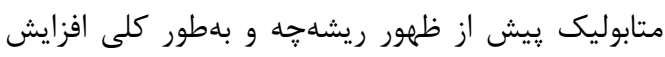

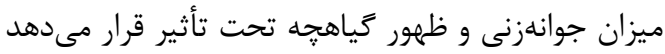

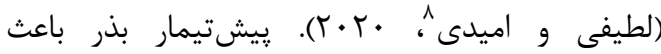

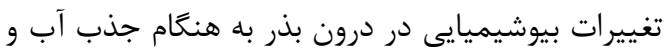

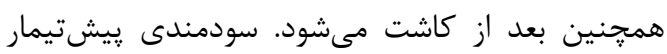
بذر بر روى رشد و نمو گياهان مربوط به اثرات مستقيم

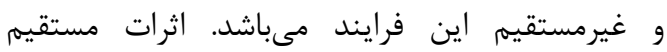
״يشتيمار بذر بر جوانهزنى، سبز شدن و سرعت رشد

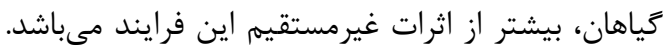

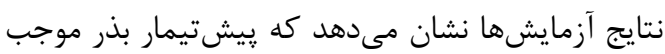
خروج سريعتر زياهجه، تحمل بهتر زياه به خشكي، Fلدهى زودتر و افزايش عملكرد گياهان نخود ( Cicer

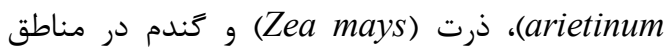
نيمه خشك مى گردد (موسوى و همكاران، 9 × . ץ). اسيد ساليسيليك يا اورتوهيدروكسى بنزوئيك اسيد و تركيبات متعلق به آن از مشتقات فنلهاى گياهى مىباشد كه معمولاً قابل حل در آب بوده و يك تركيبات تركيب آنتىاكسيدانتى و از جمله هورمونهاى گياهى است

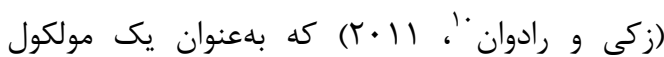

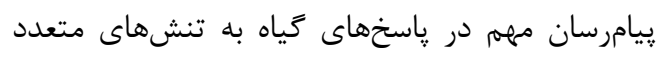

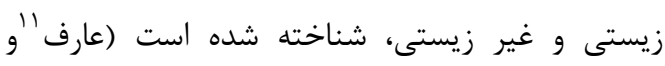

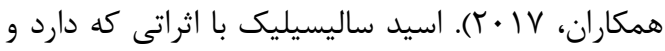

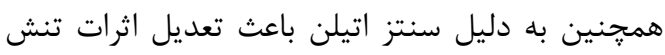

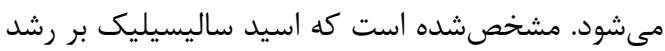

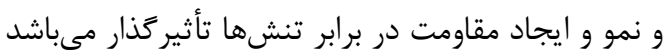

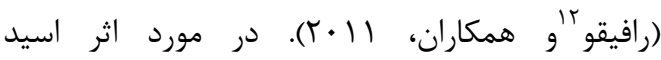
ساليسيليك بر جوانهزنى بذر ززارش شده كه كه در

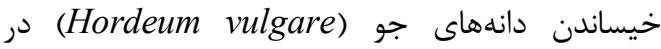
محلول اسيد ساليسيليك افزايش درصد جوانهزئ

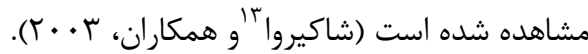

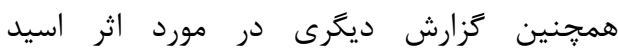

\footnotetext{
${ }^{8}$ Latifi and Omidi

${ }^{9}$ Moosavi

${ }^{10}$ Zaki and Radwan

${ }^{11}$ Arefi

${ }^{12}$ Rafique

${ }^{13}$ Shakirova
}

كندم (Triticum aestivum L.) مورد نياز بشر را تأمين مى كند و بهعنوان مهمترين كياه

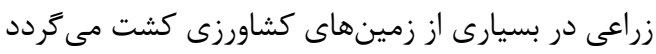
و عامل بسيار مهمى براى يايدارى سياسى و اقتصادى و ورئي

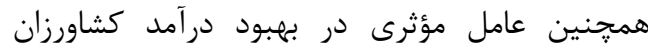

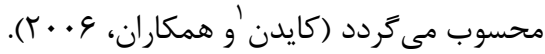
مهممترين جالش در توليد محصولات كشاورزى از جمله كَندم، تنش كممآبى است. كمآبى مهرمترين عامل

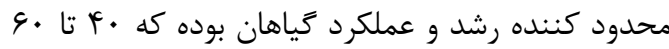
درصد اراضى كشاورزى جهان را تحت تأثير قرار مىدهد و باعث كاهش رشد و عملكرد در گَندم نيز مىشود

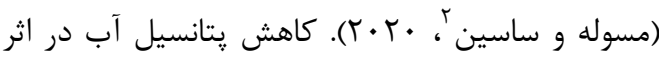

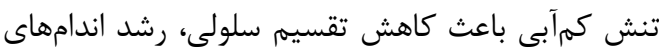
كياه، كاهش فتوسنتز خالص، سنتز يروتئين و تغيير توازن هورمونى مى كردد (جى وُو همكاران، • ( • (Y). تنش كمآبى از عواملى است كه بر جوانهزنى بذر اثر

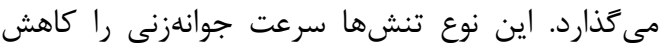
مىدهد و در تنشهايى با شدت بالا علاوه بر جوانهزنى

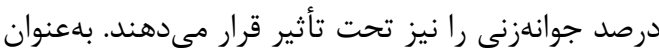
مثال زَارش شده است كه در ارقام مختلف گَندم در

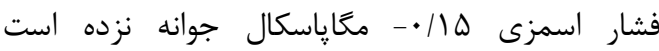

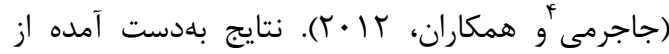

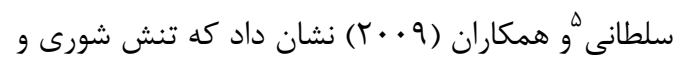

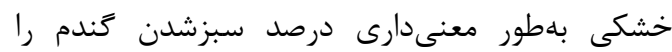

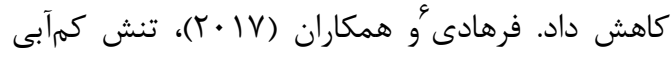
در مناطق خشك و نيمه خشك را يكى از مهمترين

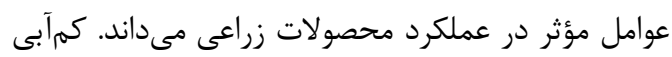

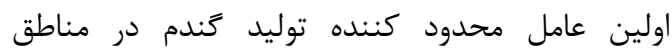
نيمهخشك مىباشد. محدوديت آب طى رشد و نمو زايشى (قبل از رسيدگى فيزيولوزيك) عملكرد و اجزاى

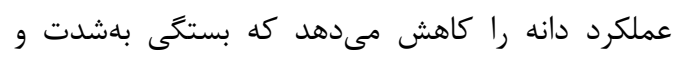

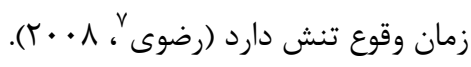

\footnotetext{
${ }^{1}$ Kaydan

${ }^{2}$ Masouleh and Sassine

${ }^{3} \mathrm{Ji}$

${ }^{4}$ Jajromy

${ }^{5}$ Soltani

${ }^{6}$ Farhadi

${ }^{7}$ Razavi
} 


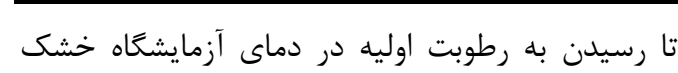

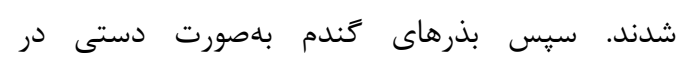

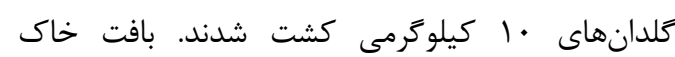

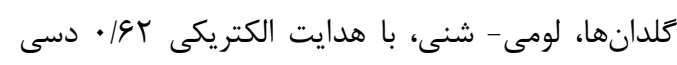

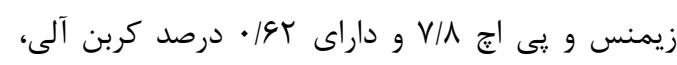

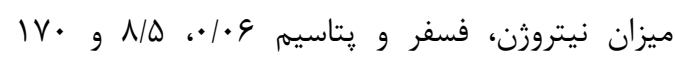
ميلى

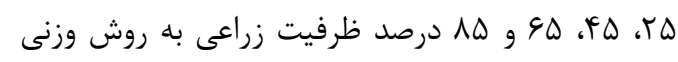

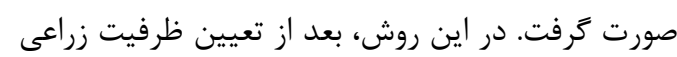

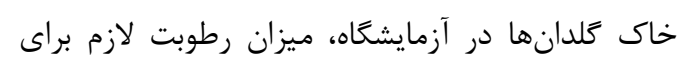

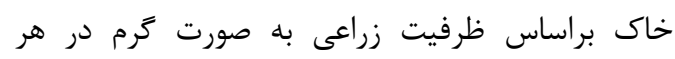

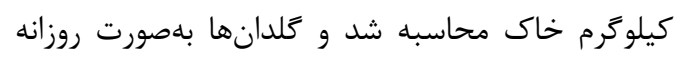

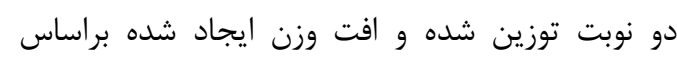

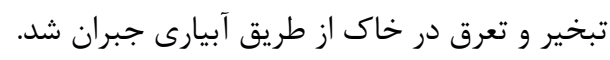

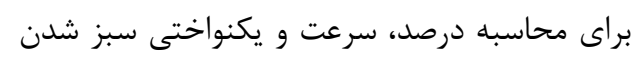

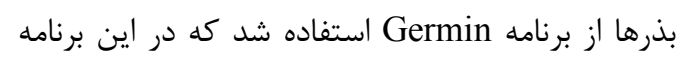

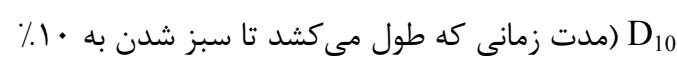

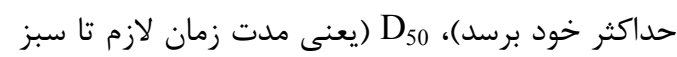

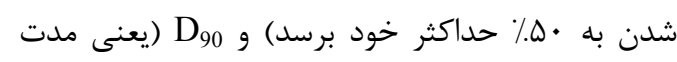

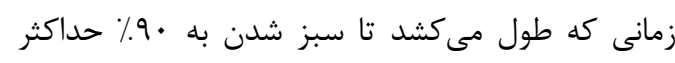

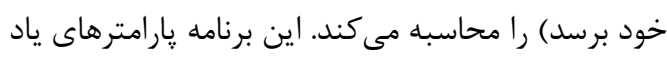

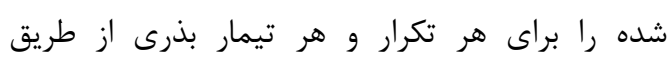

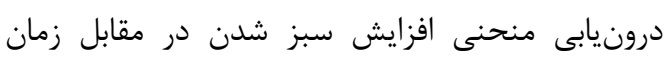

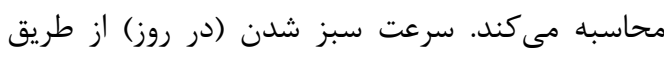

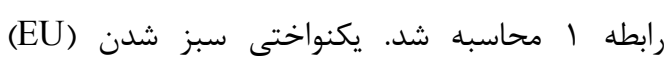

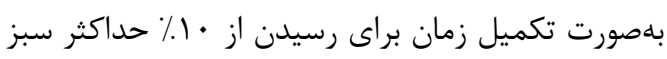

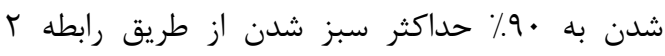

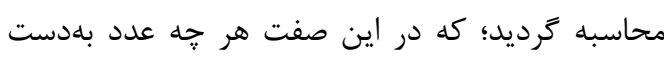

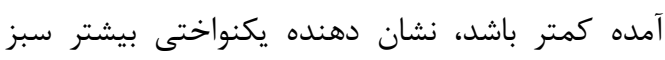

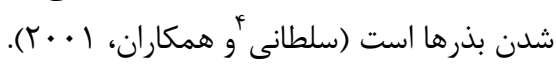

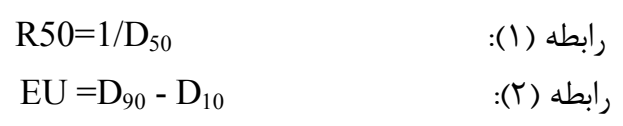

مدت زمان رسيدن به · •ا، تا • ج درصد سبز شدن

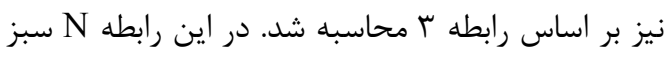

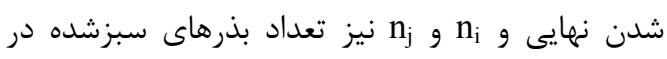
مدت زمان بين th

\footnotetext{
${ }^{4}$ Soltani

${ }^{5}$ Coolbear
}

ساليسيليك بر جوانهزنى كندم نشان داده كه اسيد

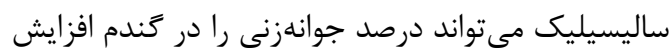

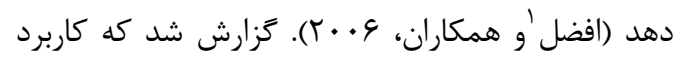

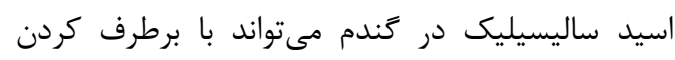

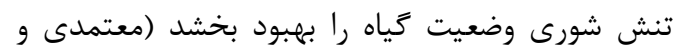

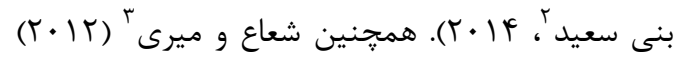

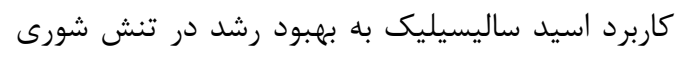

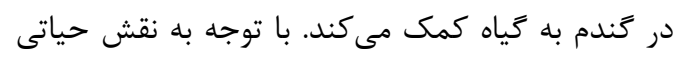

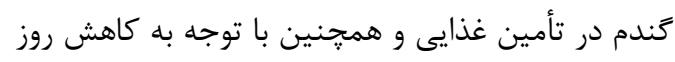
افزون منابع آبهاى شيرين جهت كُون كشاورزى، اين

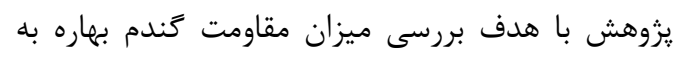

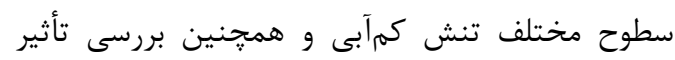

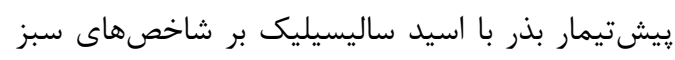

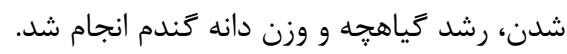

\section{مواد و روشها}

آزمايش بلهورت فادور راكتوريل در قالب طرح كاملاً تصادفى با سه تكرار در سال هو با دا در كلخانه دانشكده علوم كشاورزى دانشكاه محقق اردبيلى اجرا كرديد.

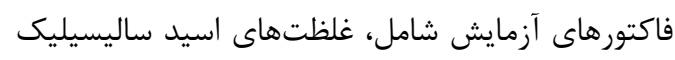

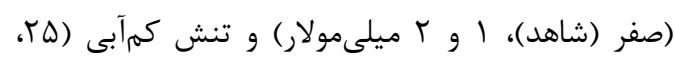

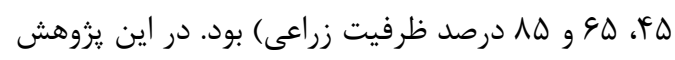

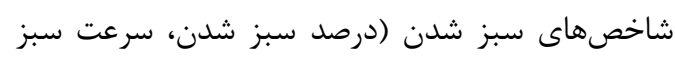

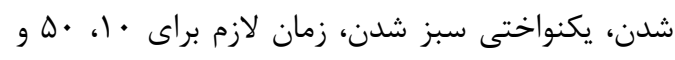

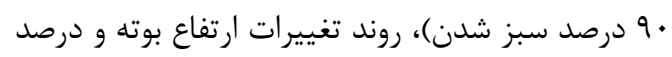

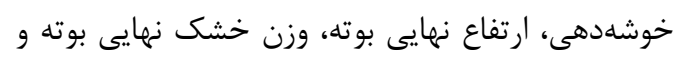
وزن دانه اندازميرى شده ارتفاع نهايى

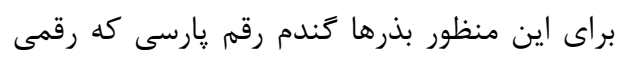

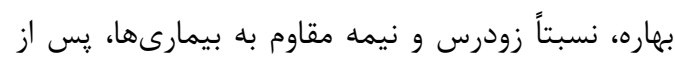

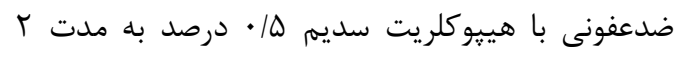

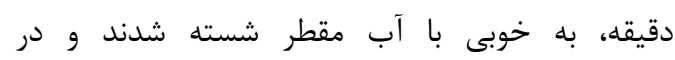

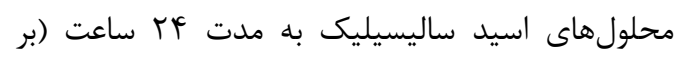

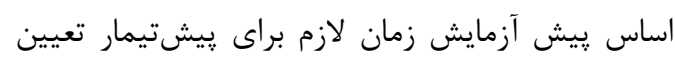

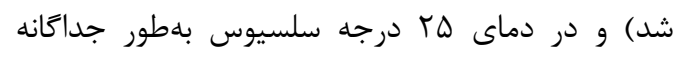

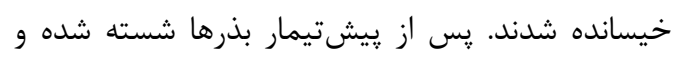

\footnotetext{
${ }^{1}$ Afzal

${ }^{2}$ Motamdy and Banysaid

${ }^{3}$ Shoa and Miri
} 


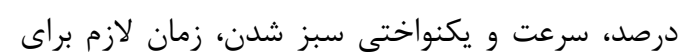

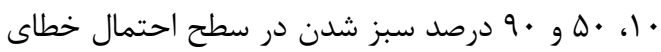

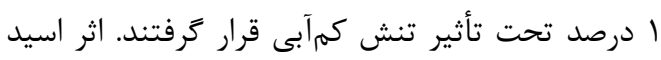

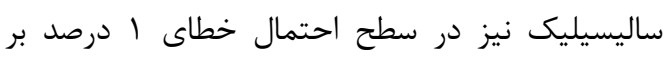

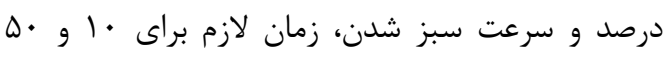

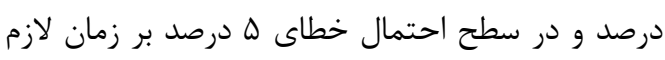

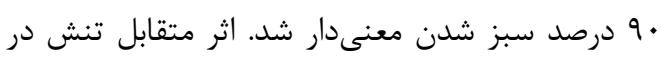

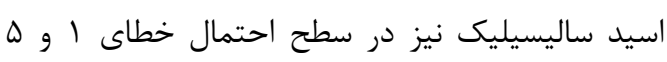

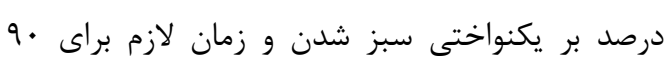

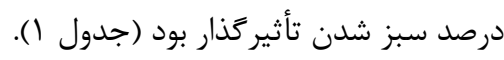
مقادير ييشبينى نشان داد، تغييرات درصد و سر سرعت سبز شدن كندم در طى تنش كمرآبى بلهصورت

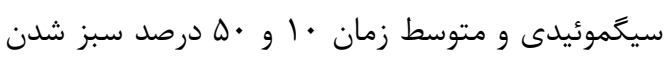

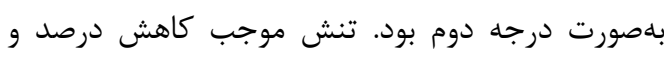

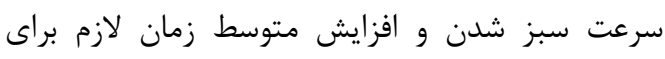

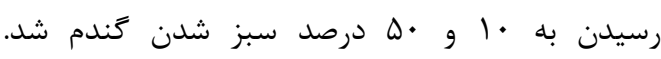

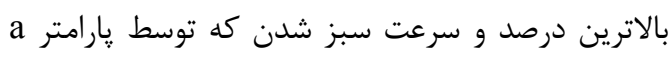

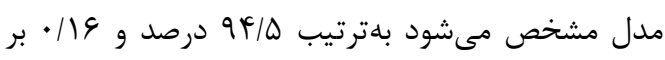

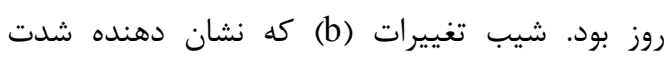

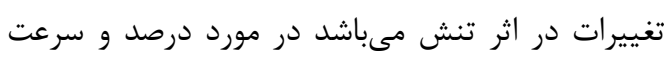

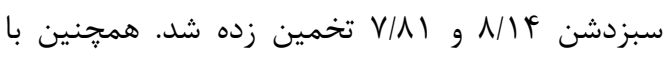

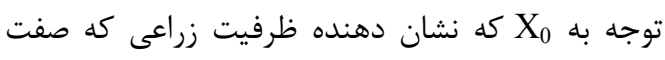

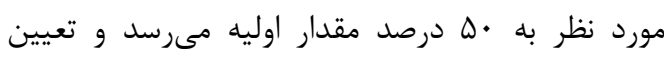

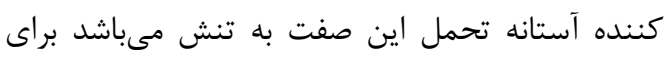

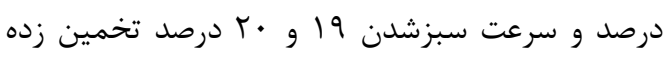

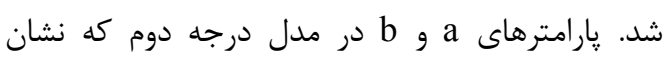

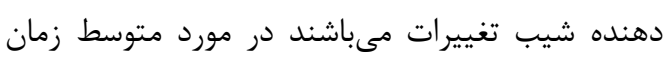

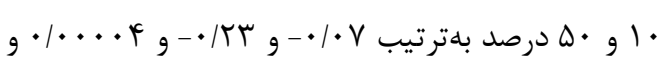

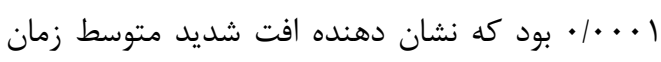

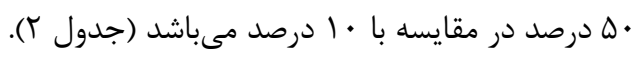

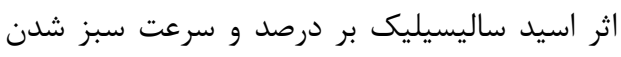

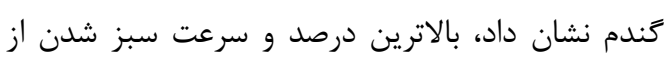

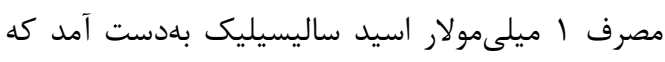

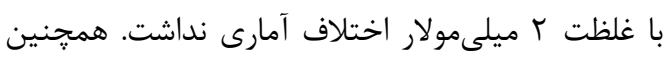

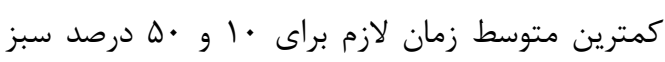
شدن از اين غلظت مشاهده شد (شكل ()).
رابطه (ए):

$\mathrm{D}_{10,50,90}=\mathrm{t}_{\mathrm{i}}+\left[\left(\mathrm{N} / 2-\mathrm{n}_{\mathrm{i}}\right)\left(\mathrm{t}_{\mathrm{j}}-\mathrm{t}_{\mathrm{i}}\right)\right] /\left(\mathrm{n}_{\mathrm{j}}-\mathrm{n}_{\mathrm{i}}\right)$ براى برسى تغييرات ارتفاع بوته و ميزان سنبلهدهى

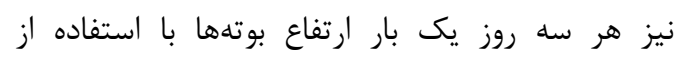

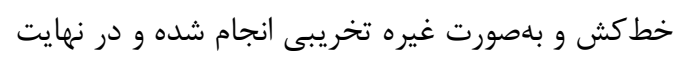

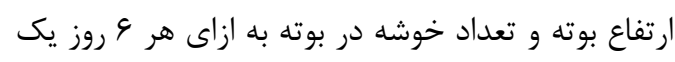

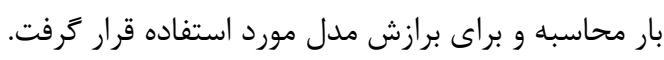

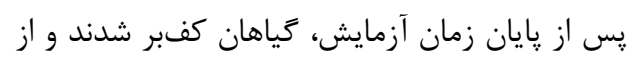

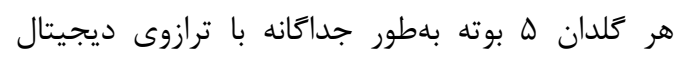

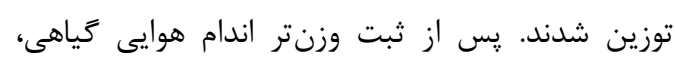

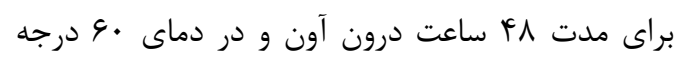

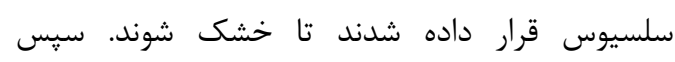

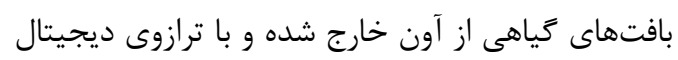

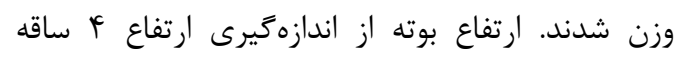

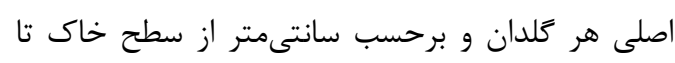

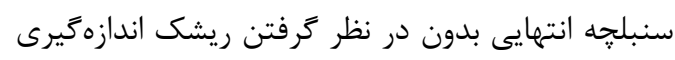

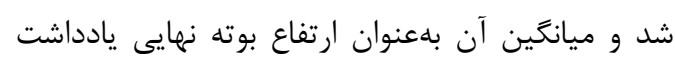

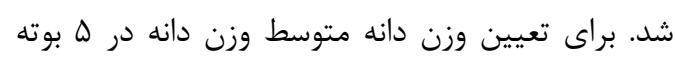
بعد از رسيدگى كامل و برداشت كردن تعيين گرديد. تجزيه و تحليل دادهها با استفاده از نرمافزار

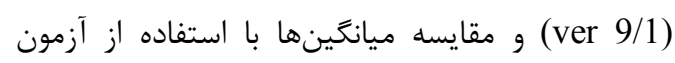

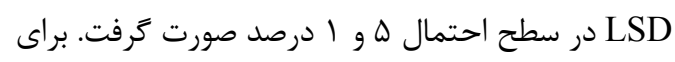

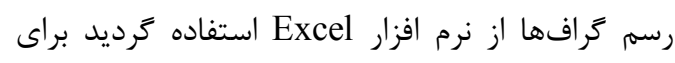

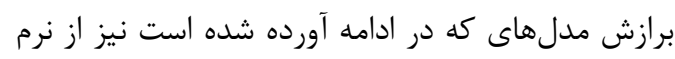
افزار Sigma plot (11) استفاده شد. f $=y_{0}+b \times x$

مدل درجه دوم $\mathrm{f}=\mathrm{y}_{0}+\mathrm{a} \times \mathrm{x}+\mathrm{b} \times \mathrm{x}^{\wedge} 2$

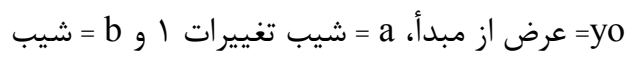
تغييرات

f=a/(1+exp(-(x-x0)/b)) مدل سينگً $f=y_{0}+(a / x)+\left(b / x^{\wedge} 2\right)$

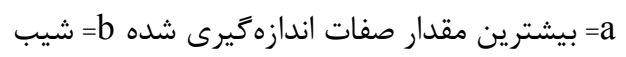

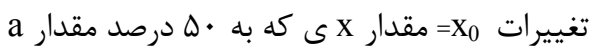
مىرسد.

نتايج و بحث شاخصهاى سبز شدن نتايج مربوط به شاخصهاى سبز سبز شدن نشان داد، 


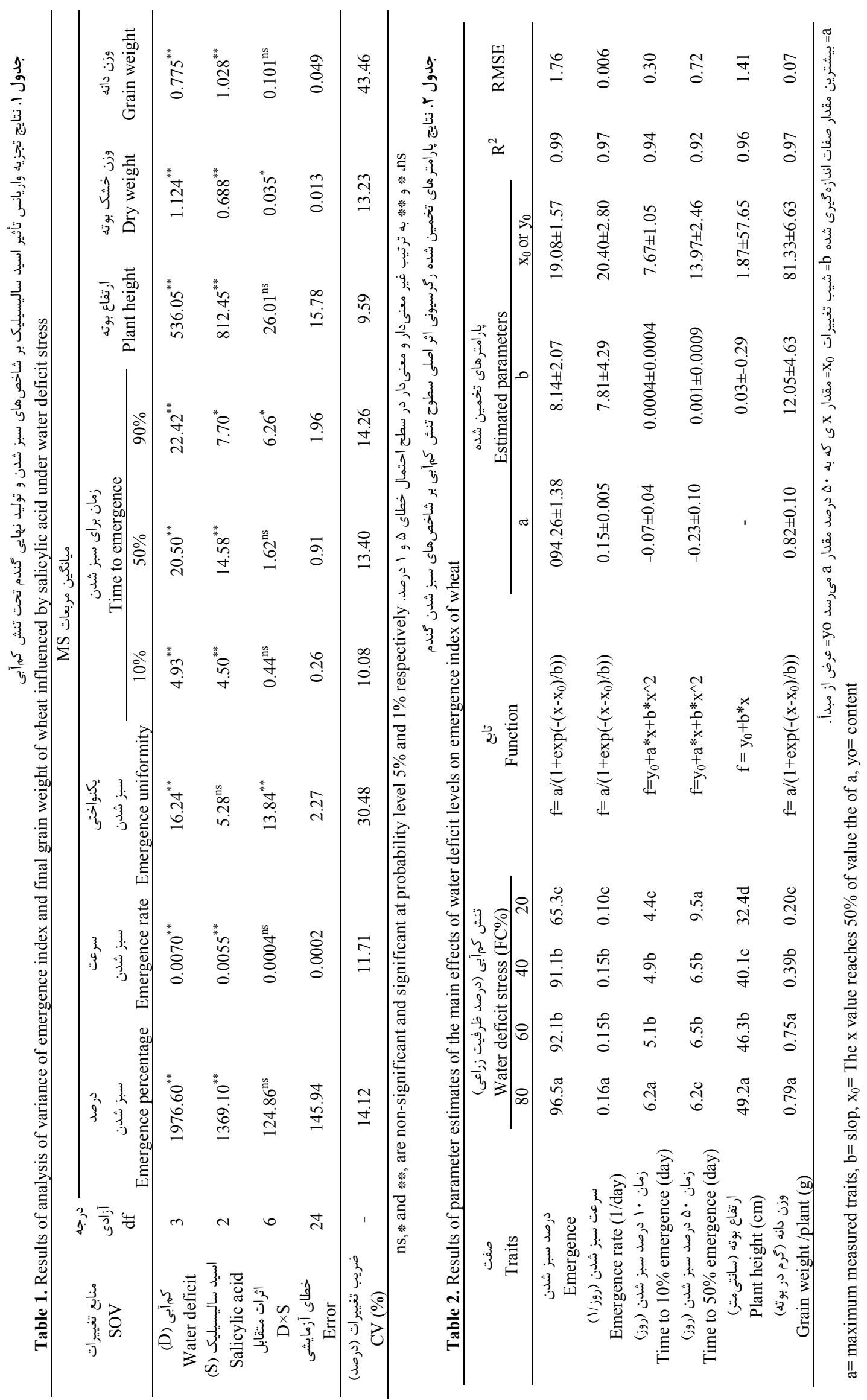




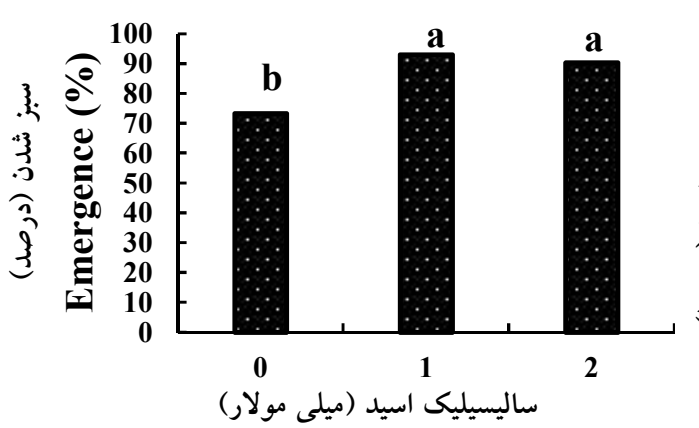

Salicylic acid (mM)

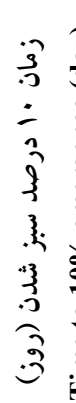

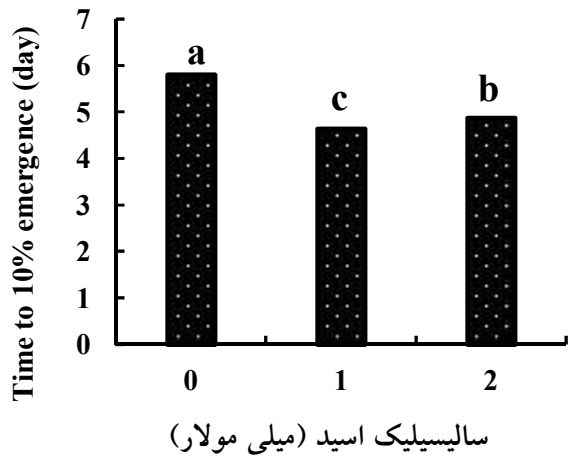

Salicylic acid (mM)

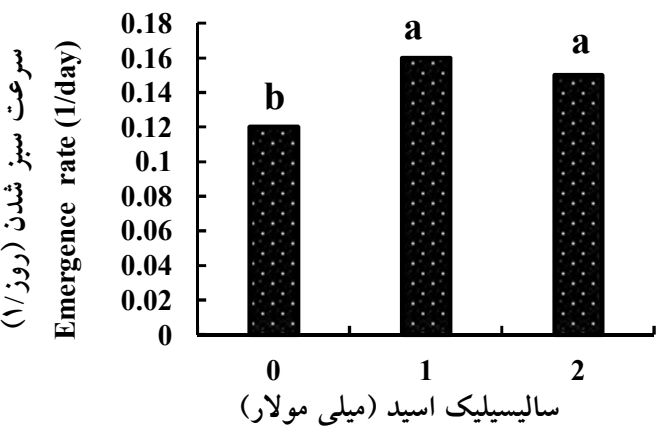

Salicylic acid (mM)
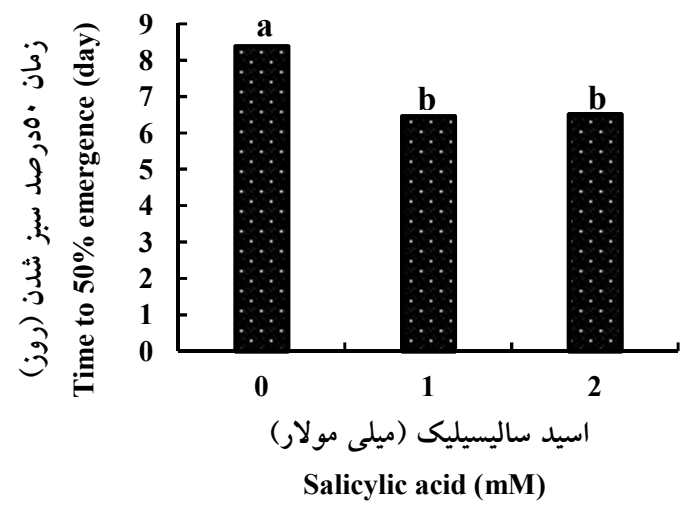

Fig. 1. Mean comparison of the main salicylic acid effect on the emegence index of wheat

خياهجههاى سبز شده در مزرعه افزايش يابد. علاوه بر

جوانهزنى، سرعت و يكنواختى جوانهزدن و سبز شدن نيز

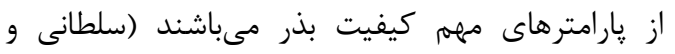

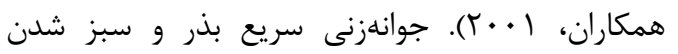
يكنواخت در استقرار موفق زياهان تحت شرايط تنش

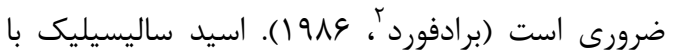

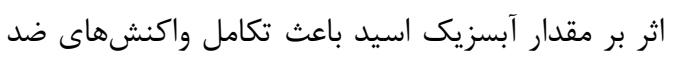

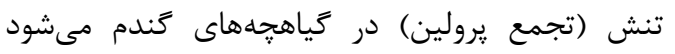

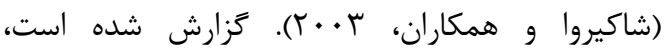
ييشتيمار بذر باعث افزايش درصد، سرعت و يكنواختى

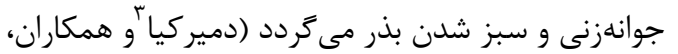

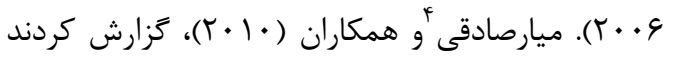
كه بالاترين درصد سبز كردن، شاخص سبزكردن و وكمارن

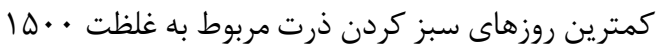

\footnotetext{
${ }^{2}$ Bradford

${ }^{3}$ Demir Kaya

${ }^{4}$ Miyar Sadeghi
}

$$
\begin{aligned}
& \text { مقادير پيشبينى برهم كنش تنش در اسيد }
\end{aligned}
$$

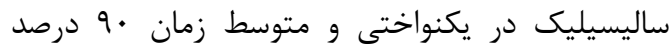

$$
\begin{aligned}
& \text { سبز شدن نشان داد، يكنواختى در شرايط عدم استفاده }
\end{aligned}
$$

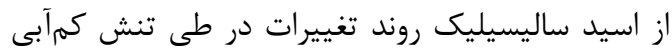

$$
\begin{aligned}
& \text { لعاريتمى بوده، ولى با استفاده از غلظت ا ميلىمولار }
\end{aligned}
$$

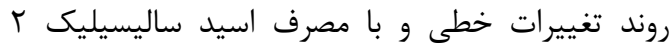

$$
\begin{aligned}
& \text { ميلىمولار تغييرات بلهورت درجه دوم تغيير يافت. }
\end{aligned}
$$

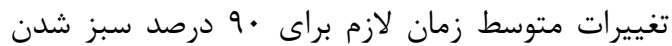

$$
\begin{aligned}
& \text { نيز در غلظتهاى صفر و r ميلىمولار بهصورت درجه } \\
& \text { دوم و در غلظت ا بهصورت خطى بود (جدول س). } \\
& \text { اثر اسيد ساليسيليك در جلوگيرى از تنشهاى } \\
& \text { زيستى و غير زيستى مثل UV، كمآبى، شورى، گرما، }
\end{aligned}
$$

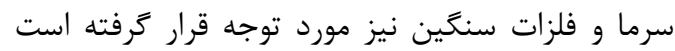

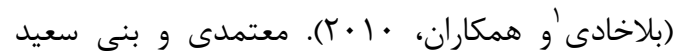

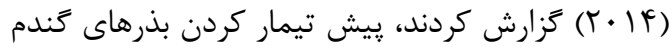

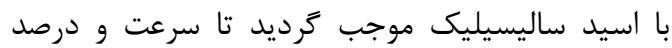

\footnotetext{
${ }^{1}$ Belkhadi
} 

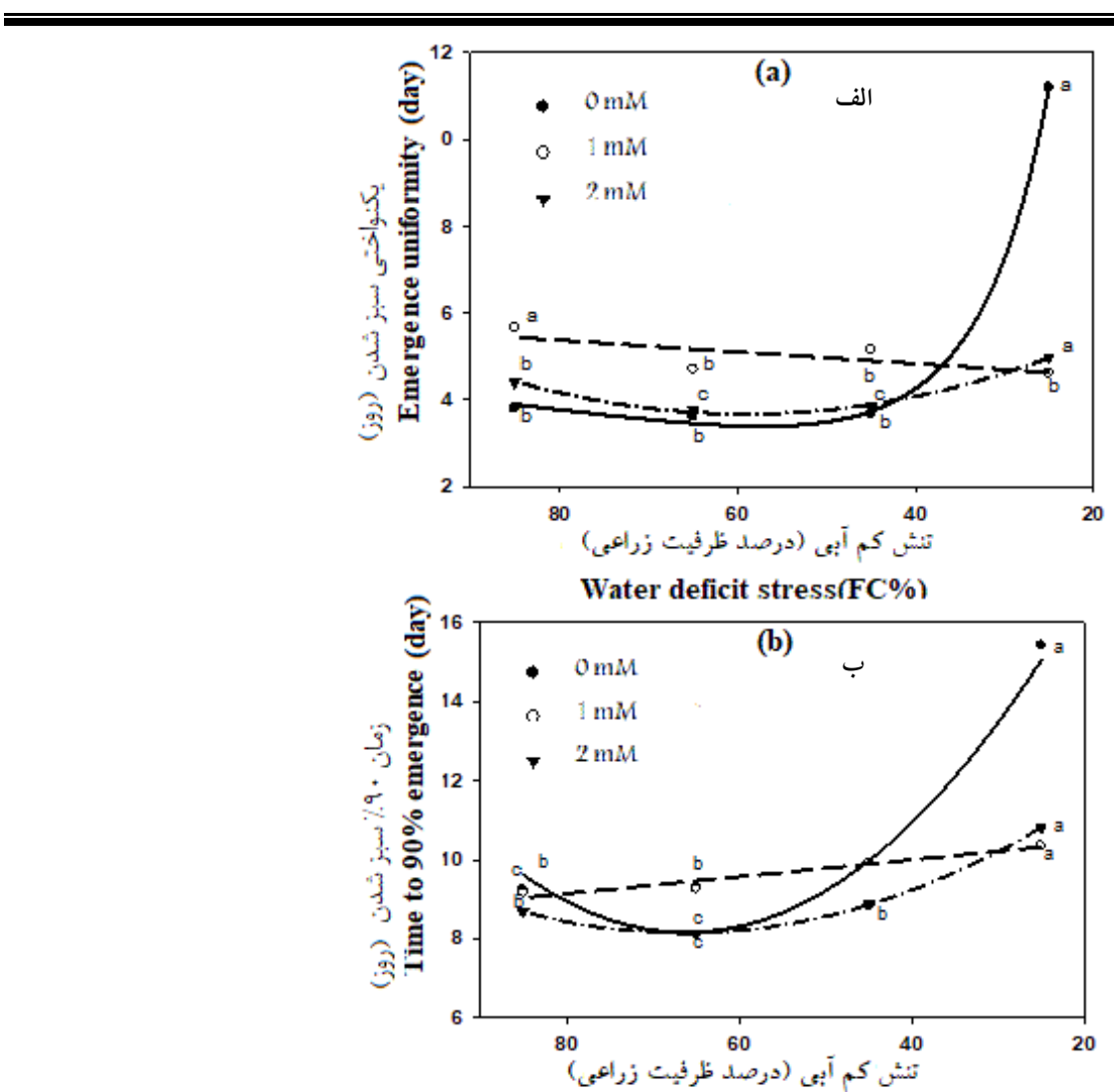

Water deficit stress(FC\%)

شكل r. تغييرات ركرسيونى اثر متقابل تنش كمآبى و اسيد ساليسيليك بر يكنواختى سبز شدن (الف) و زمان • 9 درصد سبز شدن (ب)

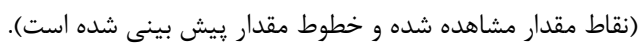

Fig. 2. Regression variations in interaction of water deficit stress and salicylic acid on emergence uniformity (a) and time to $90 \%$ emergence (b) (points are observed data and lines are prediced values)

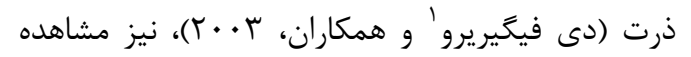
شد. كاهش فرايند جوانهزنى در اثر تنش كم آبى مى دئواند با كاهش جذب آب توسط بذرها ارتباط داشته باشد كه باعث مىشود فعاليتهاى متابوليكى جوانهزنى در داخل

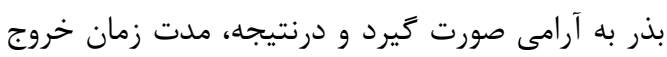
ريشهجه از بذر افزايش و از اين رو سرعت جوانهزنى نيز

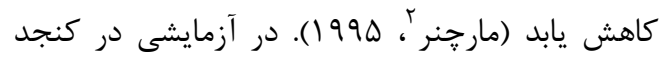
مشخص شد كه تأثير پيشتيمار (Sesamum indicum) بذر و تنش شورى بر درصد سبز شدن زياهجه و زمان

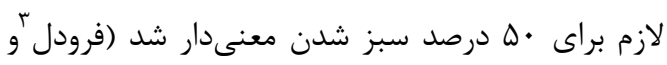

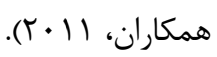

\footnotetext{
${ }^{1}$ De Figueiredo

2 Marchner

${ }^{3}$ Froodel
}

$$
\begin{aligned}
& \text { ميكرومولار اسيد ساليسيليك بود. اسيد ساليسيليك از }
\end{aligned}
$$

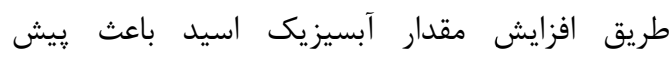

$$
\begin{aligned}
& \text { ساز ₹ارى نسبت به تنشهاى اكسيداتيو مىشود. با توجه } \\
& \text { به اينكه بذرهايى كه سريعتر جوانه مىزنند و }
\end{aligned}
$$

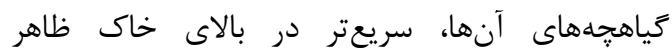

$$
\begin{aligned}
& \text { مىشوند، زودتر از بقيه عمل فتوسنتز خود را آغاز كرده } \\
& \text { در مقايسه با گَياهجههاى همجوار شانس توليد گياهان } \\
& \text { استقرار يافته و بزرگتر را خواهد داشت (ميارصادقى و ويلهو }
\end{aligned}
$$

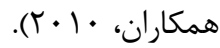

$$
\begin{aligned}
& \text { در اين آزمايش نيز تيمارهايى كه سبز شدن سريعتر } \\
& \text { داشتند، ديخر صفات ارزيابى شده براى نمو زياهجه نيز } \\
& \text { افزايش يافت. در اين آزمايش با افزايش تنش كمآبى، } \\
& \text { روند كاهش معنى دارى در درصد و سرعت جوانهزنى اين }
\end{aligned}
$$

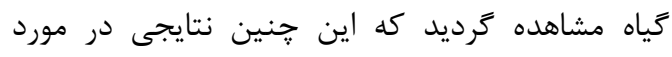

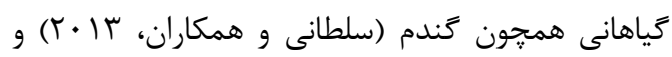


در كياه مىشود كه اين امر مىتواند احتمال ير شدن كامل دانهها را به همراه داشته باشد (جدول عاء). مقادير پيشبينى نشان داد، كاربرد اسيد ساليسيليك

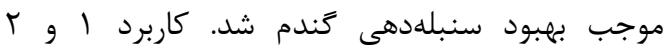
ميلىمولار اسيد ساليسيليك موجب بهبود سنبلهدهى از

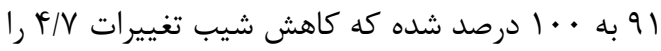
بههمراه داشت. بِيشتيمار از طريق افزايش طول دوره سنبله دهيد و ملايمتر كردن روند تغييرات سنبلهدهى موجب كاهش شيب تغييرات در اين صفت مىشود

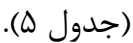

به نظر مىرسد در ابتداى فصل رشد و قبل از ساقه رفتن، از آنجائى كه تمام ماده خشك حاصل دئ توليد برك

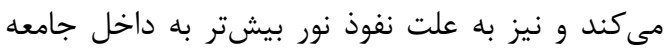

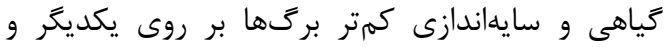
جذب خالص و در نتيجه تنفس كمتر ميزان سرعت رشد

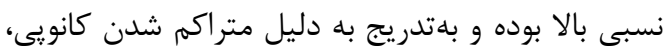
ميزان سرعت رشد نسبى روندى كاهشى داشته و در آخر فصل رشد به دليل بيرى كياه، افزايش بافتهاى

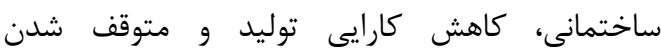
فعاليتهاى گياه در تخصيص مواد فتوسنتزى به به اندامهاى رويشى و زايشى ميزان سرعت رشد نسبى به

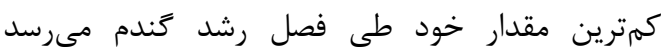

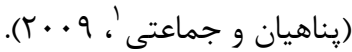

سرعت رشد محصول در مراحل اوليه به دليل كامل

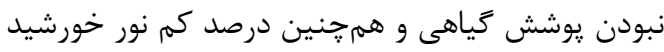
كه توسط كياهان جذب مىشود كم مى بـاشد زيرا سطح برى افزايش يافته و نور كمترى از ميان كانويى به سطح

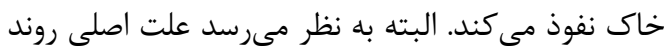
نزولى سرعت رشد محصول در طول دوره پايانى رشد مربوط به كاهش مقدار شاخص سطح برى و نيز كاهش

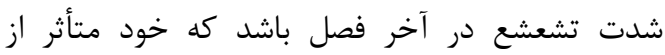

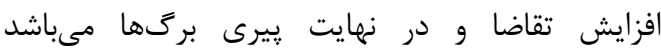

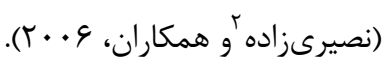

\footnotetext{
${ }^{1}$ Panahyan and Jamaati
}

${ }^{2}$ Nasirzadeh
ميزان و سرعت رشد بوته

نتايج تغييرات ارتفاع بوته در زمانهاى مختلف نشان داد، ميزان رشد كندم در تنشهاى مختلف و غلظتهاي مختلف اسيد ساليسيليك متفاوت بود. روند ارتفاع بوته كَندم بلصورت سيگموئيدى بود. تنش كمآبى موجب كاهش ميزان ارتفاع كَندم شد (شكل گr). بالاترين ميزان

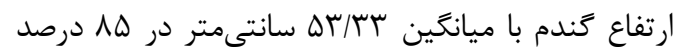
ظرفيت زراعى و كمترين ميزان رشد نيز با ميانكين سانتىمتر مربوط به تنش شديد (هV/VV

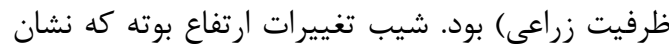
دهند سرعت رشد مىباشد در شرايط بدون تنش

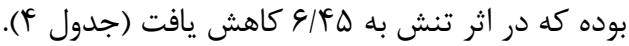
مقادير يیشبينى نشان داد، تغييرات ارتفاع بوته در

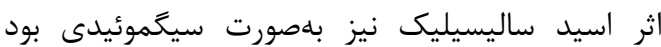
(شكل ץ). كاربرد اسيد ساليسيليك موجب بهبود ميزان و سرعت تغييرات ارتفاع بوته كَندم شد. بالاترين ميزان

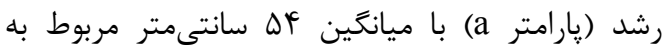
كاربرد r ميلىمولار اسيد ساليسيليك و كمترين مقدار

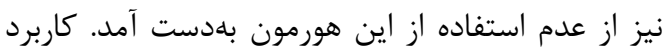
اسيد ساليسيليك موجب كاهش شيب تغييرات ارتفاع كندم و افزايش متوسط زمان رسيدن به بالاترين مقدار

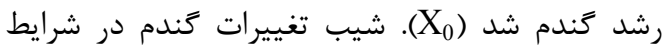

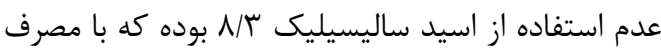

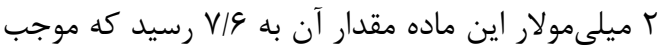

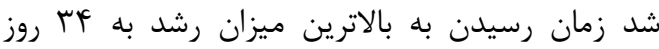
افزايش يابد كه اين باعث مىشود دوره رشد در كياه افزايش بيدا كند (جدول ها ه). نتايج سنبلهدهى نشان داد، سنبلهدهى گَندم در سطوح مختلف اسيد ساليسيليك و تنش كمآبى متفاوت بود. سنبلهدهى كندم در تنشهاى ملايم افزايش يافته

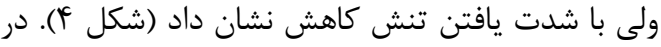

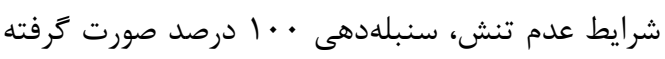
كه در اثر تنش شديد ميزان سنبلهدهى به •و بو درصد

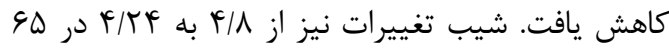
درصد ظرفيت زراعى رسيده، ولى با شدت يافتن تنش

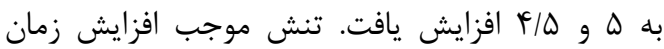

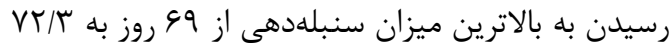

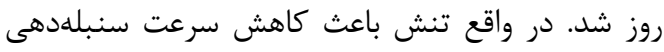


جدول r. پارامترهاى تخمين شده ركرسيونى اثر متقابل تنش كمآبى و اسيد ساليسيليك بر شاخصهاى سبز شدن گندم

Table 3. Parameter estimates of the interaction of water deficit stress and salicylic acid on wheat emergence index

\begin{tabular}{|c|c|c|c|c|c|c|c|}
\hline صفت & \multirow{2}{*}{$\begin{array}{c}\text { اسيد ساليسيليك) } \\
\text { (ميلى مولار) } \\
\text { Salicylic } \\
\text { (mM)acid }\end{array}$} & \multirow{2}{*}{$\begin{array}{c}\text { تابع } \\
\text { Funaction }\end{array}$} & \multicolumn{5}{|c|}{$\begin{array}{c}\text { پارامترهاى تخمين شده } \\
\text { Estimated parameters }\end{array}$} \\
\hline Traits & & & $\mathrm{a}$ & $\mathrm{b}$ & $\mathrm{x}_{0}$ or $\mathrm{y}_{0}$ & $\mathrm{R}^{2}$ & RMSE \\
\hline \multirow{3}{*}{$\begin{array}{c}\text { يكنواختى سبز شدن } \\
\text { (روز) } \\
\text { Emegence } \\
\text { uniformity } \\
\text { (day) }\end{array}$} & 0 & $\mathrm{f}=\mathrm{y}_{0}+(\mathrm{a} / \mathrm{x})+\left(\mathrm{b} / \mathrm{x}^{\wedge} 2\right)$ & $\begin{array}{c}- \\
537.4 \pm 68.9\end{array}$ & $1537.3 \pm 128.5$ & $0.08 \pm 0.76$ & 0.99 & 0.19 \\
\hline & 1 & $\mathrm{f}=\mathrm{y}_{0}+\mathrm{b} * \mathrm{x}$ & - & $0.01 \pm 0.009$ & $4.29 \pm 0.54$ & 0.51 & 0.41 \\
\hline & 2 & $\mathrm{f}=\mathrm{y}_{0}+\mathrm{a}^{*} \mathrm{x}+\mathrm{b}^{*} \mathrm{x}^{\wedge} 2$ & $-0.13 \pm 0.01$ & $0.0011 \pm 0.0001$ & $7.54 \pm 0.30$ & 0.99 & 0.08 \\
\hline \multirow{3}{*}{$\begin{array}{l}\text { زمان · درصد (روز) } 90 \% \\
\text { Time to } 90 \% \\
\text { emegence (day) }\end{array}$} & 0 & $\mathrm{f}=\mathrm{y}_{0}+\mathrm{a} * \mathrm{x}+\mathrm{b}^{*} \mathrm{x}^{\wedge} 2$ & $-0.53 \pm 0.23$ & $0.004 \pm 0.002$ & $25.98 \pm 5.84$ & 0.90 & 1.70 \\
\hline & 1 & $\mathrm{f}=\mathrm{y}_{0}+\mathrm{b}^{*} \mathrm{x}$ & - & $-0.02 \pm 0.003$ & $10.85 \pm 0.23$ & 0.93 & 0.17 \\
\hline & 2 & $\mathrm{f}=\mathrm{y}_{0}+\mathrm{a}^{*} \mathrm{x}+\mathrm{b}^{*} \mathrm{x}^{\wedge} 2$ & $\begin{array}{c}- \\
0.20 \pm 0.008 \\
\end{array}$ & $0.001 \pm 7.54$ & $15.00 \pm 0.20$ & 0.99 & 0.06 \\
\hline \multirow{3}{*}{$\begin{array}{c}\text { وزته (كرم) بون } \\
\text { Dry weight (g) }\end{array}$} & 0 & $\mathrm{f}=\mathrm{y}_{0}+\mathrm{b} * \mathrm{x}$ & - & $0.011 \pm 0.001$ & $-0.02 \pm 7$ & 0.97 & 0.05 \\
\hline & 1 & $\mathrm{f}=\mathrm{y}_{0}+\mathrm{b} * \mathrm{x}$ & - & $0.010 \pm 0.001$ & $0.30 \pm 0.06$ & 0.98 & 0.04 \\
\hline & 2 & $\mathrm{f}=\mathrm{y}_{0}+\mathrm{b} * \mathrm{x}$ & - & $0.018 \pm 0.0008$ & $0.11 \pm 0.05$ & 0.99 & 0.03 \\
\hline
\end{tabular}

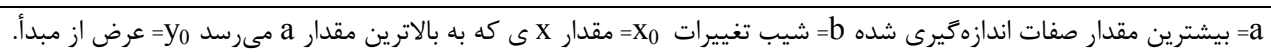
$a=$ maximoum measured traits, $b=$ slop, $x_{0}=$ The $x$ value reaches the highest value of $a$, yo= content

خشك بوته در سطح احتمال خطاى ا درصد تحت تأثير تنش كمآبى و اسيد ساليسيليك و در سطح احتمال خطاى ه درصد تحت تأثير برهم كنش آنها قرار زرفت.

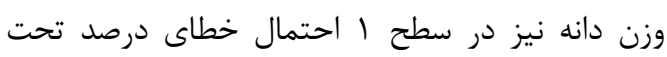
تأثير تنش كمآبى و اسيد ساليسيليك قرار كرفتند

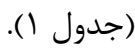
مقايسه ميانگينها نشان داد، تنش كمآبى موجب كاهش وزن دانه شد. روند تغييرات وزن دانه بهصورت سيخموئيدى بود (جدول ץ). مقايسه ميانخين مربوط به

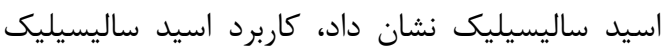
موجب افزايش وزن دانه شد. بلهورى كه مصرف ب ميلى مولار اسيد ساليسيليك بالاترين مقادير اين صفت را به خودش اختصاص داد. برهم كنش تنش كم آبى در

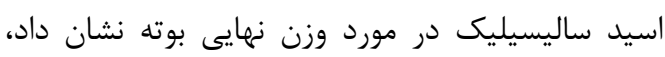

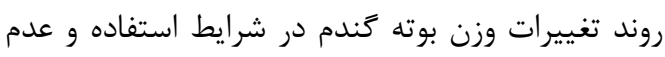
استفاده از اسيد ساليسيليك بهصورت خطى تغيير ييدا كرد. تغييرات وزن نهايى بوته نيز در شرايط عدم استفاده از اسيد ساليسيليك بهصورت خطى تغيير پيدا كرد. مقادير يیيشبينى نشان داد، در شرايط عدم كاربرد اسيد

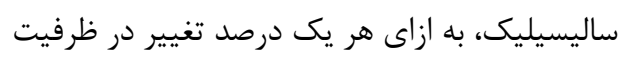

كاربرد اسيد ساليسيليك از طريق بهبود سرعت سبز شدن باعث مىشود كه گياه در رقابت با گياهان ديخر

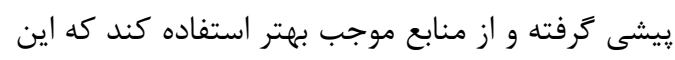

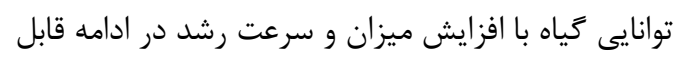
مشاهده است (موسوى و همكاران، 9 × . Y). ارتفاع بوته و وزن دانه ارتفاع بوته كندم تحت تأثير تنش كمآبى و اسيد ساليسيليك قرار گرفت (جدول ()). نمودار مربوط به تهنيه روند تغييرات ارتفاع بوته در تنش كممآبى نشان داد، در اثر تنش ارتفاع بوته بهصورت خطى كاهش يافت. مقادير

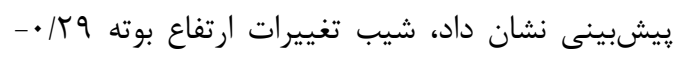

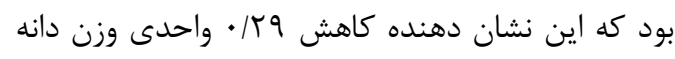
به ازاى هر يك واحد افزايش تنش كمآبى است (جدول

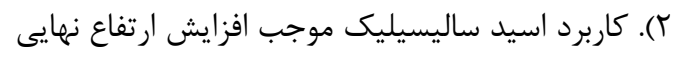

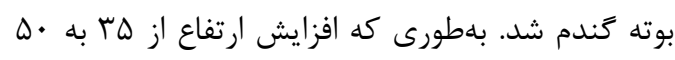

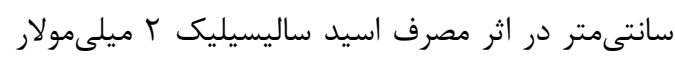
بdدست آمد (شكل ه). نتايج تجزيه واريانس وزن دانه گَندم نشان داد، وزن . 

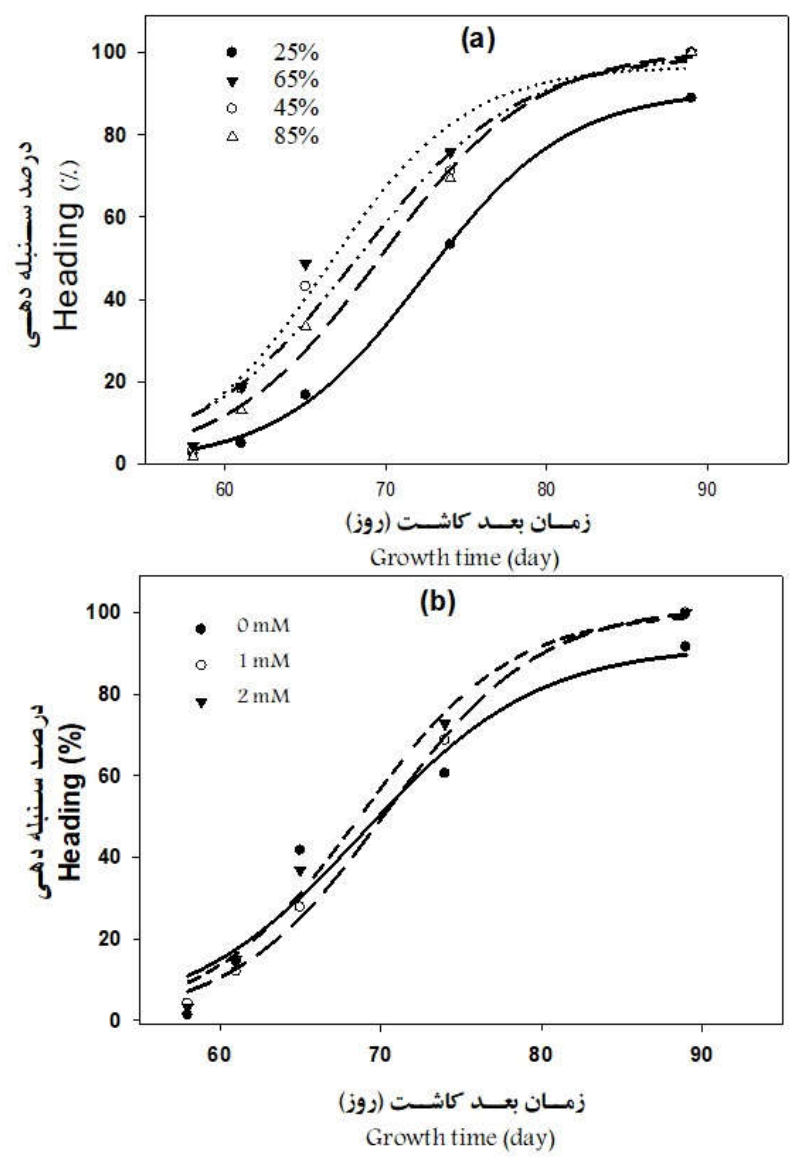

شكل س. تغييرات ركرسيونى اثر تنش كمآبى (الف) و اسيد ساليسيليك (ب) بر ارتفاع بوته كَندم در زمانهاى مختلف (نقاط مقدار مشاهده شده و خطوط مقدار ييش بينى شده است).

Fig. 3. Regression variations in the effect of water deficit stress (a) and salicylic acid (b) on height of wheat over differents times (points are observation data and lines are prediced values)

در تيمار آبيارى معادل • ه درصد آبى گياه به ثبت رسيد (فراست؛

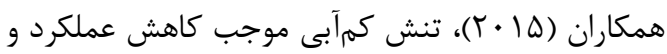
اجزاى عملكرد جو شد كه با نتايج اين آزمايش روى

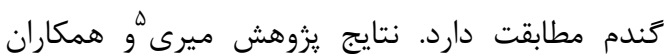

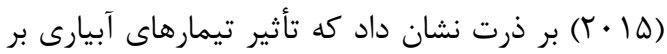
عملكرد دانه، آب مصرفى و وزن هزار دانه معنى دار شد. مطالعات نشان داده است كه كمبود آب منجر به ونه كاهش محتواى نسبى آب در برگها مىشود. مقادير

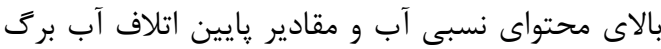
بهعنوان شاخصهاى مهرم براى وضعيت آب ريشنيتهاد

\footnotetext{
${ }^{3}$ Ferast

${ }^{4}$ Saberi
}

${ }^{5}$ Miri
زراعى، وزن نهايى بوته || | • • گرم كاهش ييدا مى كند كه اين تغييرات در شرايط مصرف ا ميلى مولار اسيد

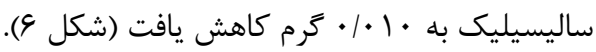
طبق تحقيقات صورت گرفته كمبود آب از عوامل اصلى افت عملكرد در گَندم مىباشد (فولى وُ همكاران،

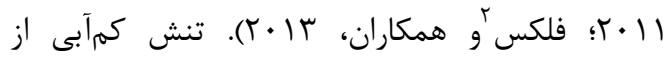
طريق كاهش سرعت رشد گياه باعث كاهش ارتفاع مىشود و هر جه زمان اعمال تنش به مراحل انتهايى فصل رشد نزديكتر باشد تنش تأثير كمترى بر ارتفاع كياه دارد كه در نهايت كاهش عملكرد را به همراه دارد.

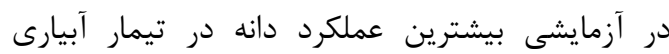
معادل • ه درصد نياز آبى زياه و كمترين عملكرد دانه

\footnotetext{
${ }^{1}$ Foley

${ }^{2}$ Flexas
} 

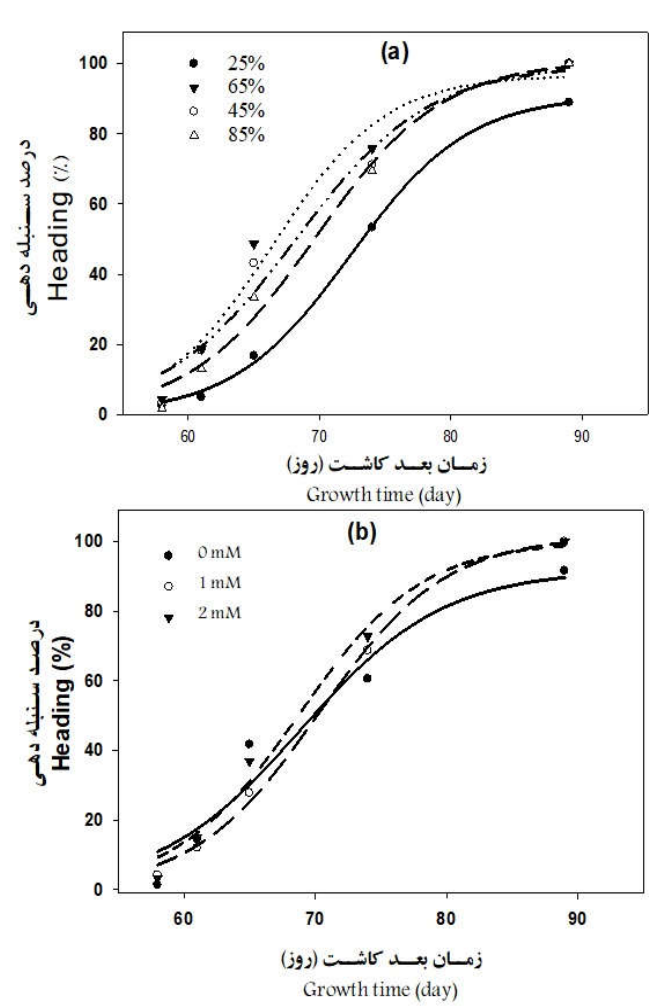

شكل Norror! No text of specified style in document. ساليسيليك (ب) بر درصد خوشهدهى كَندم (نقاط مقدار مشاهد ركاه شده و خطوط مقدار ييش بينى شده است).

Fig. 4. Regression variations in the effect water deficit stress (a) and salicylic acid (b) on heading of wheat (points are observation data and lines are prediced values)
شدهاند (جونس'و همكاران، 1 • (Y). در كزارش وكيلى

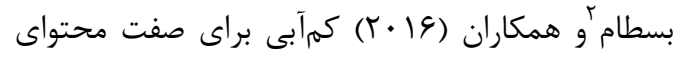

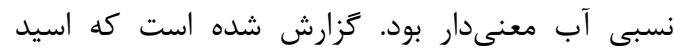

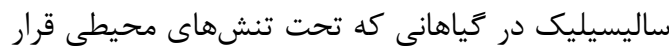

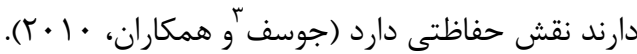
با توجه به نتايج بهدست آمده از اين تحقيق كاربرد

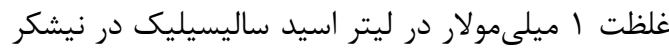
موجب افزايش ميزان ارتفاع، وزنتر اندام هوايى، وزنتر ريشه و كاهش نفوذيذيرى نسبى غشاء به سديم برى إنى

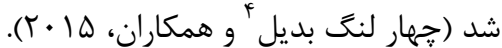
طى يزوهشى در گياه ذرت زَزارش شد اسيد ساليسيليك سبب افزايش معنى دار وزن هزار دانه ترديد

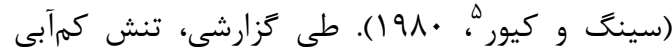
سبب كاهش تعداد كيسول در بوته، تعداد دانه در هر

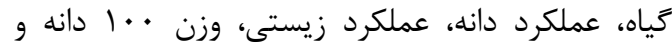

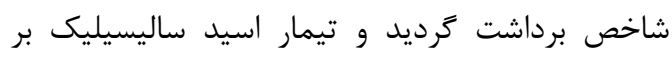

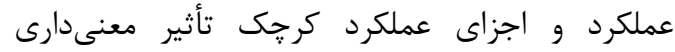
داشتند. بيشترين عملكرد دانه مربوط به تيمار اسيد

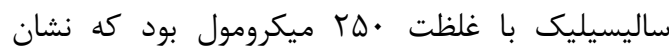

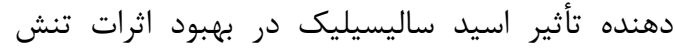

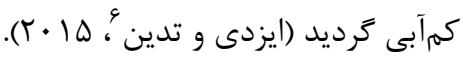

$$
\text { نتيجه گيرى }
$$

بهطور كلى مشاهده مىشود كه تنش كمآبى موجب

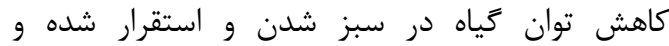

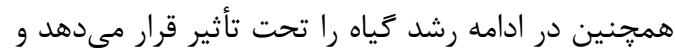
در نهايت ميزان توليد را نيز به شدت كاهش ميدين آدهد. همجنين نتايج نشان مىدهد كه بين كاربرد اسيد ساليسيليك و تنش كمآبى برهمكنش معنى دارى به جز براى برخى از صفات وجود نداشت و اين هورمون داراى

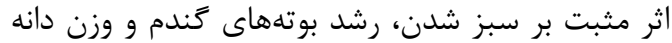

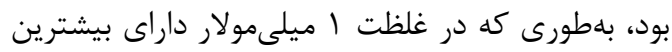
تأثير حذارى مشاهده مىشود. بهور.

${ }^{1}$ Gunes

${ }^{2}$ Vakili Bostam

${ }^{3}$ Joseph

${ }^{4}$ Chaharlang Badil

${ }^{5}$ Singh and Kaur

${ }^{6}$ Izadi and Tadion 
كَنجه و همكاران: تأثير يِيش تيمار بذر با ساليسيليك اسيد بر شاخصهاى سبز شدن...

جدول F. يارامترهاى تخمين شده رگرسيونى اثر سطوح تنش كمآبى بر ارتفاع و سنبلهدهى گَندم

Table 4. Estimated regression parameters of the effects of water deficit stress on growth height and heading of wheat.

\begin{tabular}{|c|c|c|c|c|c|c|c|}
\hline \multirow{2}{*}{$\begin{array}{l}\text { صفت } \\
\text { traits }\end{array}$} & \multirow{2}{*}{$\begin{array}{c}\text { (ظنش كمآبى } 1 \text { (ظرفيت زراعى) } \\
\text { Water deficit } \\
\text { (FC) }\end{array}$} & \multirow{2}{*}{$\begin{array}{c}\text { تابع } \\
\text { Funaction }\end{array}$} & \multicolumn{5}{|c|}{$\begin{array}{c}\text { گارامترهاى تخمين شده } \\
\text { Estimated parameters }\end{array}$} \\
\hline & & & $\mathrm{a}$ & $\mathrm{b}$ & $\mathrm{x}_{0}$ & $\mathrm{R}^{2}$ & RMSR \\
\hline \multirow{4}{*}{$\begin{array}{c}\text { ارتفاع بوته } \\
\text { (سانتى متر) } \\
\text { Plant } \\
\text { height } \\
\text { (cm) }\end{array}$} & 85 & $\mathrm{f}=\mathrm{a} /\left(1+\exp \left(-\left(\mathrm{x}-\mathrm{x}_{0}\right) / \mathrm{b}\right)\right)$ & $53.33 \pm 1.73$ & $8.30 \pm 0.92$ & $32.49 \pm 1.10$ & 0.98 & 2.61 \\
\hline & 65 & $\mathrm{f}=\mathrm{a} /\left(1+\exp \left(-\left(\mathrm{x}-\mathrm{x}_{0}\right) / \mathrm{b}\right)\right)$ & $52.13 \pm 2.16$ & $8.21 \pm 1.14$ & $33.45 \pm 1.38$ & 0.97 & 3.20 \\
\hline & 45 & $\mathrm{f}=\mathrm{a} /\left(1+\exp \left(-\left(\mathrm{x}-\mathrm{x}_{0}\right) / \mathrm{b}\right)\right)$ & $46.41 \pm 1.66$ & $7.30 \pm 1.02$ & $31.50 \pm 1.20$ & 0.97 & 2.89 \\
\hline & 25 & $\mathrm{f}=\mathrm{a} /\left(1+\exp \left(-\left(\mathrm{x}-\mathrm{x}_{0}\right) / \mathrm{b}\right)\right)$ & $37.77 \pm 1.32$ & $6.45 \pm 0.94$ & $32.61 \pm 1.12$ & 0.97 & 2.42 \\
\hline \multirow{4}{*}{$\begin{array}{c}\text { سنبلهدهى (/) } \\
\text { Heading } \\
\text { (\%) }\end{array}$} & 85 & $\mathrm{f}=\mathrm{a} /\left(1+\exp \left(-\left(\mathrm{x}-\mathrm{x}_{0}\right) / \mathrm{b}\right)\right)$ & $100.91 \pm 7.42$ & $4.81 \pm 0.94$ & $69.67 \pm 1.42$ & 0.98 & 6.39 \\
\hline & 65 & $\mathrm{f}=\mathrm{a} /\left(1+\exp \left(-\left(\mathrm{x}-\mathrm{x}_{0}\right) / \mathrm{b}\right)\right)$ & $96.69 \pm 10.05$ & $4.27 \pm 1.46$ & $66.43 \pm 1.95$ & 0.96 & 9.77 \\
\hline & 45 & $\mathrm{f}=\mathrm{a} /\left(1+\exp \left(-\left(\mathrm{x}-\mathrm{x}_{0}\right) / \mathrm{b}\right)\right)$ & $99.68 \pm 10.63$ & $5.06 \pm 1.49$ & $68.15 \pm 2.13$ & 0.97 & 9.18 \\
\hline & 25 & $\mathrm{f}=\mathrm{a} /\left(1+\exp \left(-\left(\mathrm{x}-\mathrm{x}_{0}\right) / \mathrm{b}\right)\right)$ & $90.98 \pm 2.44$ & $4.50 \pm .35$ & $72.35 \pm 0.48$ & 0.99 & 2.04 \\
\hline
\end{tabular}

$\mathrm{a}=$ maximum measured traits, $\mathrm{b}=$ slop, $\mathrm{x}_{0}=$ The $\mathrm{x}$ value reaches $50 \%$ of value the of $\mathrm{a}$

جدول ه. يارامترهاى تخمين شده ركرسيونى اثر اصلى اسيد ساليسيليك بر ارتفاع بوته و سنبلهدهى گَندم

Table 5. Estimated regression parameters of effect salicylic acid on plant height and heading of wheat

\begin{tabular}{|c|c|c|c|c|c|c|c|}
\hline \multirow{2}{*}{$\begin{array}{c}\text { صفت } \\
\text { traIts }\end{array}$} & \multirow{2}{*}{$\begin{array}{c}\text { (سيد ساليسيليك ميلى مولار) } \\
\text { Salicylic acid } \\
\text { (mM) }\end{array}$} & \multirow{2}{*}{$\begin{array}{c}\text { تابع } \\
\text { Funaction }\end{array}$} & \multicolumn{5}{|c|}{$\begin{array}{c}\text { ֶارامترهاى تخمين شده } \\
\text { Estimated parameters }\end{array}$} \\
\hline & & & $\mathrm{a}$ & $\mathrm{b}$ & $\mathrm{x}_{0}$ & $\mathrm{R}^{2}$ & RMSR \\
\hline \multirow{3}{*}{$\begin{array}{c}\text { ارتفاع بوته } \\
\text { Plant height } \\
\text { (cm) }\end{array}$} & 0 & $\mathrm{f}=\mathrm{a} /\left(1+\exp \left(-\left(\mathrm{x}-\mathrm{x}_{0}\right) / \mathrm{b}\right)\right)$ & $40.29 \pm 1.316$ & $8.37 \pm 0.88$ & $30.15 \pm 1.02$ & 0.98 & 1.87 \\
\hline & 1 & $\mathrm{f}=\mathrm{a} /\left(1+\exp \left(-\left(\mathrm{x}-\mathrm{x}_{0}\right) / \mathrm{b}\right)\right)$ & $47.39 \pm 1.75$ & $6.97 \pm 1.02$ & $32.24 \pm 1.21$ & 0.97 & 3.07 \\
\hline & 2 & $\mathrm{f}=\mathrm{a} /\left(1+\exp \left(-\left(\mathrm{x}-\mathrm{x}_{0}\right) / \mathrm{b}\right)\right)$ & $54.18 \pm 2.24$ & $7.60 \pm 1.10$ & $34.27 \pm 1.33$ & 0.97 & 3.46 \\
\hline \multirow{3}{*}{$\begin{array}{c}\text { سنبلددهى (/) } \\
\text { Heading } \\
(\%)\end{array}$} & 0 & $\mathrm{f}=\mathrm{a} /\left(1+\exp \left(-\left(\mathrm{x}-\mathrm{x}_{0}\right) / \mathrm{b}\right)\right)$ & $91.95 \pm 14.29$ & $5.44 \pm 2.23$ & $68.88 \pm 3.20$ & 0.94 & 11.56 \\
\hline & 1 & $\mathrm{f}=\mathrm{a} /\left(1+\exp \left(-\left(\mathrm{x}-\mathrm{x}_{0}\right) / \mathrm{b}\right)\right)$ & $100.64 \pm 3.40$ & $4.77 \pm 0.42$ & $70.28 \pm 0.64$ & 0.99 & 2.90 \\
\hline & 2 & $\mathrm{f}=\mathrm{a} /\left(1+\exp \left(-\left(\mathrm{x}-\mathrm{x}_{0}\right) / \mathrm{b}\right)\right)$ & $100.14 \pm 7.04$ & $4.70 \pm 0.91$ & $68.70 \pm 1.36$ & 0.98 & 6.25 \\
\hline
\end{tabular}

$a=$ maximum measured traits, $b=$ slop, $x_{0}=$ The $x$ value reaches $50 \%$ of value the of $a$ 


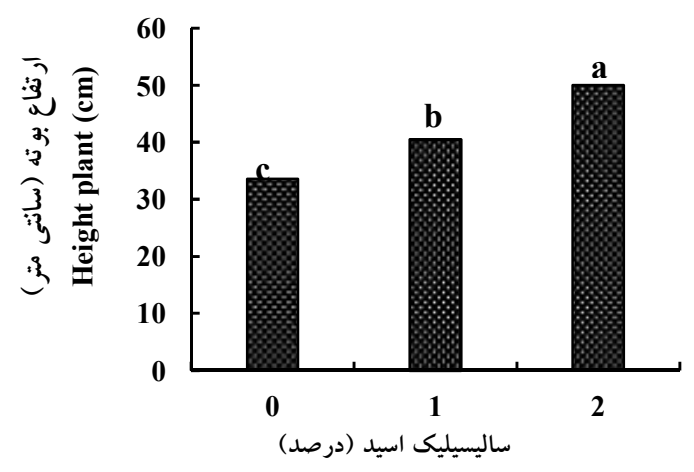

Salicylic acid(mM)

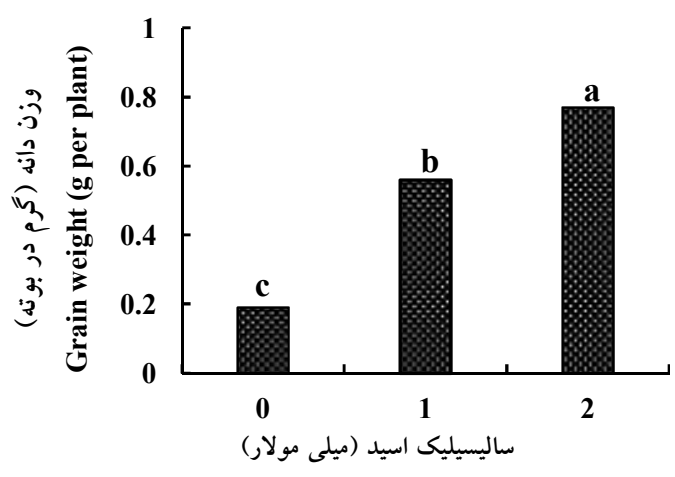

Salicylic acid(mM)

شكل ه. مقايسه ميانگين اثر اصلى اسيد ساليسيليك بر ارتفاع بوته و وزن دانه كَندم

Fig. 5. Mean comparison of the salicylic acid main effect on plant height and grain weight of wheat

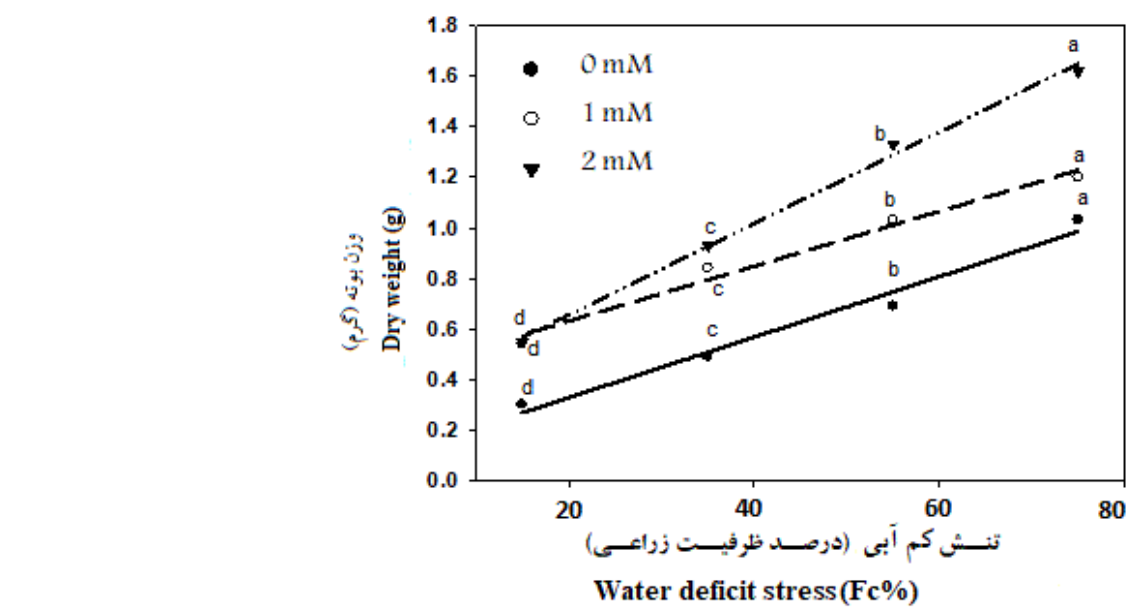

شكل و. تغييرات ركرسيونى اثرات متقابل تنش كمآبى و اسيد ساليسيليك بر وزن بوته كندم (نقاط مقدار مشاهده شده و خطوط مقدار ييش بينى .

Fig. 6. Regression variations in the effects of water deficit stress and salicylic acid on the plant weight of wheat (points are observation data and lines are prediced values).

Afzal, I., Basra, S.M.A., Faroog, M., and Nawaz, A. 2006. Alleviation of salinity stress in spring wheat by hormonal priming with ABA, salicylic acid and ascorbic acid. International Journal Agriculture Biology, 8(1): 23-28.

Aref, S., Lary yazdi, H. and Amiri, H. 2017. Interaction Copper and salicylic acid on carbohydrate content, proline, catalase activity two cultivar Vigna radiata L. Journal of Al-Zahra University (Applied Biology), 31(1): 95-111. [In Persian with English Summary].

Belkhadi, A., Hediji, H., Abbes, Z., Nouairi, I., Barhoumi, Z., Zarrouk, M., Chaibi, W., and Djebali, W. 2010. Effects of exogenous salicylic acid pre-treatment on cadmium toxicity and leaf lipid content in Linum usitatissimum L. Ecotoxicology and Environmental Safety, 73(5): 1004-1011. https://doi.org/10.1016/j.ecoenv.2010.03.009

Bradford, K.J. 1986. Manipulation of seed water relations via osmotic priming to improve germination under stress conditions. HortScience (USA), 21: 1105-1112.

Chaharlang Badi, F, Barry, M., Shamili, M. and Tahmasebi, Z. 2015. Effect of different salicylic acid levels on growth improvement and some physiological and biochemical indices of 
sugarcane (Saccharum officinarum) under salinity stress. Environmental Stresses in Agricultural Sciences, 8(2): 307-317. [In Persian with English Summary].

Coolbear, P. 1984. The effect of low temperature pre-sowing treatment on the germination performance and membrane integrity of artificially aged tomato seeds. Journal of Experimental Botany, 35: 1609-1617. https://doi.org/10.1093/jxb/35.11.1609

De Figueiredo, E, Al buquerque, M.C. and De Carvalho, N.M. 2003. Effect of the type of environmental stress on the emergence of sunflower (Helianthus annuus L.), soybean (Glycine max L.), and maize (Zea mays L.) seeds with different levels of vigor. Seed Science Technology, 31: 465-479. https://doi.org/10.15258/sst.2003.31.2.23

Demir Kaya, M., Okçu, G., Atak, M., Çikili, Y. and Kolsarici, O. 2006. Seed treatment to overcome salt and drought stress during germination in sunflower (Helianthus annuus L.). European Journal of Agronomy, 24(4): 291-295. https://doi.org/10.1016/j.eja.2005.08.001

Farhadi, H. Azizi, M. and Nemat, S.H. 2017. The effect of water deficit stress on morphological characteristics and yield components of landraces (Trigonella foenum-graecum L.) fenugreek eight. Journal of Crop Science Research in Arid Regions, 1(1):120-131. [In Persian with English Summary].

Ferast, M. 2010. Effect of water deficit stress on agronomic, physiological, and biochemical characteristics of safflower cultivars. Master's Degree in Agriculture, Faculty of Agriculture and Natural Resources, Islamic Azad University, Arak Branch. 134p. [In Persian with English Summary].

Flexas, J., Niinemets, U., Galle, A., Barbour, M.M. and Centritto, M. 2013. Diffusional conductances to $\mathrm{CO}$ as a target for increasing photosynthesis and photosynthetic water-use efficiency. Photosynthesis Research, 117(1): 45-59. https://doi.org/10.1007/s11120-013-9844-z

Foley, J.A., Ramankutty, N., Brauman, K.A., Cassidy, E.S., Gerber, J.S., Johnston, M., and Mueller, N.D. 2011. Solutions for a cultivated planet. Nature, 478: 337-342. https://doi.org/10.1038/nature10452

Froodel S., Sadrabadi HaghighiR. and Nabavi CalatS. M. 2012. Effect of Seed Priming on Seedling Growth of Sesame (Sesamum indicum L.) under Salinity Stress. Iranian Journal of Field Crops Research, 9(3):535-543. [In Persian with English Summary].

Gunes, A., Inal, A., Adak, M.S., Bagci, E.G., Cicek, N. and Eraslan, F. 2008. Effect of drought stress implemented at pre- or post-anthesis stage on some physiological parameters as screening criteria in chickpea cultivars. Russian Journal of Plant Physiology, 55(1): 59-67. https://doi.org/10.1134/S102144370801007X

Izadi, Z. and Tadion, M. 2015. Effect of salicylic acid and spermine on yield and grain components of (Ricinus communis L.). under drought stress conditions. Environmental Stresses in Agricultural Sciences, 8(2): 159-167. [In Persian with English Summary].

Jajromy, V. 2012. Effect of drought stress on germination indices in seven wheat cultivars $(T$. aestivum L.). Journal Agronomy and Plant Breding, 8(4): 183-192.

Ji, X., Shiran, B., Wan, J., Lewis, D.C., Jenkins, C.L. D., Condon, A.G., Richards, R.A. and Dolferus, R. 2010. Importance of pre-anthesis anther sink strength for maintenance of grain number during reproductive stage water stress in wheat. Plant, Cell and Environment, 33(6): 926-942. https://doi.org/10.1111/j.1365-3040.2010.02130.x

Joseph, B., Jini, D., Sujatha, S. 2010. Insight in to role of exogenous salicylic acid on plant growth under salt environment. Asian Journal of Crop Science, 2(4): 226-235. https://doi.org/10.3923/ajcs.2010.226.235

Kaydan, D., Yagmur, M. and Okut, N. 2006. Effects of salicylic acid on the growth and some physiological characters in salt stressed wheat (Triticum aestivum L.). Tarim Bilimleri Dergisi, 
13(2): 114-119. https://doi.org/10.1501/Tarimbil_0000000444

Latifi, S.A. and Omidi H. 2020. Effect of priming on seed germination and rice seedling characteristics of anbarboo cultivar, under water deficit tension. Scientific Journal of Crop Physiology, 11: 5-14. [In Persian with English Summary].

Marchner, H. 1995. Mineral Nutrition of Higher Plants. Academic Press. 889p.

Masouleh, S.S.S., and Sassine, Y.N. 2020. Molecular and biochemical responses of horticultural plants and crops to heat stress. Ornamental Horticulture, 26(2): 148-158. https://doi.org/10.1590/2447-536x.v26i2.2134

Miri, H.R, Shokati, H.H. and Armin, M. 2015. Response of yield and yield components of maize under the influence of relative dryness of root and potassium fertilizer. Nursing Agriculture (Research and Development), 35-42. [In Persian with English Summary].

Miar Sadeghi S., Shakari F., Fotouet R. and Zangani, A. 2010. Effect of pre-treatment with salicylic acid on vigor and seedlings growth of canola under water deficit conditions. Plant Biology, 2: 55-70. [In Persian with English Summary].

Moosavi, A., Tavakkol Afshari, R., Sharif-Zadeh, F. and Aynehband, A. 2009. Effect of seed priming on germination characteristics, polyphenol oxidase and peroxidase activities of four amaranth cultivars. Journal Food Agricultural and Environmental, 7(3-4): 353-358.

Motamedi, M. and Bany Said, A.K. 2014. Effect of salicylic acid on germination and seedling growth of wheat cultivars under salt stress conditions (Triticum aestivum L.). Journal of Plant Production Sciences, 3(2): 43-57. [In Persian with English Summary].

Nasirzadeh, A., Hosseini Marvost, S.U. and Mazaherian, D. 2006. Effect of density on growth physiological indices in three maize cultivars in Marvast region of Yazd. Proceedings of the $9^{\text {th }}$ Iranian Congress of Agronomy and Plant Breeding, University of Tehran, 234p. [In Persian with English Summary].

Panahyan, M. and Jamaati, S. H. 2009. Study of variation trend of growth indices in lentil under drought stress. Australian Journal of Basic and Applied Sciences, 3(4): 4314-4326.

Rafique, N., Raza, H., Qasim, M., and Iqbal, N. 2011. Pre-sowing application of ascorbic acid and salicylic acid to seed of pumpkin and seedling response to salt. Pakistan Journal of Botany, 43(6): 2677-2682.

Razavi, R. 2008. Effect of irrigation elimination on wheat growth stages on water consumption efficiency and its quantitative and qualitative yield. Journal of Soil and Water Sciences, 22(1): 137-144. [In Persian with English Summary].

Saberi, M.H., Nikkhah, H.R., Tajaly, H. and Arezjo, A. 2015. Effects of seasonal drought stress on yield and determination of the best tolerance index in promising barley strata. Agriculture (Research and Construction), 27-34. [In Persian with English Summary].

Shakirova, F.M., Shakhbutdinova, A.R., Bezrukova, M.V., Fatkhutdionova, R.A. and Fatkhutdionova, D.R. 2003. Changes in the hormonal status of wheat seedling induced by salicylic acid and salinity. Plant Science, 164: 317-322. https://doi.org/10.1016/S01689452(02)00415-6

Shoa, M. and Miri, H. 2012. Reducing the effects of salinity stress on the morphophysiological properties of wheat through the use of salicylic acid. Electronic Journal of Crop Production, 5: 71-88. [In Persian with English Summary].

Singh, G. and Kaur, M. 1980. Effect of growth regulators on podding and yield of mung bean (Vigna radiata (L.) Wilczek). Indian Journal Plant Physiology 23: 366-370.

Soltani, A., Galeshi, S. Zainali, E. and Latifi, N. 2001. Germination, seed reserve utilization and seedling growth of chickpea as affected by salinity and seed size. Seed Science and Technology, 
كنجه و همكاران: تأثير بيش تيمار بذر با ساليسيليك اسيد بر شاخصهاى سبز شدن...

30(1): 51-60.

Soltani, E. Kamkar, B. Galeshi, S. and Akramghaderi, F. 2009. The effect of seed aging on wheat emergence on the response of environmental stress. Electronic Journal of Crop Production, 2(2): 43-58. [In Persian with English Summary].

Soltani, E., Soltani, A. and Oveisi, M. 2013. Modeling seed aging effect on wheat seedling emergence in drought stress: Optimizing germin program to predict emergence pattern. Journal of Crops Improvement, 15(2): 147-160. [In Persian with English Summary].

Vakili Bostam, Sh., Ramezanpur, S.S., Soltanlou, H., Zainili-Nezhad, Kh. and Brzuy, A. 2016. Study of drought tolerance characteristics in mutagenic wheat line at germination and adult plants. Environmental stresses in Agricultural Sciences, 10(1): 45-53. [In Persian with English Summary].

Zaki, R.N. and Radwan, T.E. 2011. Improving wheat grain yield and its quality under salinity conditions at a newly reclaimed soil by using different organic sources as soil or foliar applications. Journal of Applied Sciences Research, 7: 42-55. 
Research Article

\title{
Effect of Seed Priming by Salicylic Acid on Emergence Indices and Grain Weight of Wheat (Triticum aestivum Parsi var.) under Water Deficit Stress
}

\author{
Asgar Ganje ${ }^{1}$, Ali Ebadie ${ }^{2}$, Ghasem Parmoon ${ }^{3, *}$, Soodabeh Jahanbaksh ${ }^{2}$
}

\section{Extended Abstract}

Introduction: Water deficit stress is one of the important factors affecting seed germination. This stress decrease germination rate and affects germination percentage under high levels as well. Seed priming improves germination by changing metabolic activities before radicle emergence. This investigation was conducted to evaluate the effect of seed priming by salicylic acid on the emergence index and grain weight of spring wheat under water deficit stress.

Material and Method: These experiments were conducted as factorial based on the completely randomized design with three replicates in the greenhouse of the Faculty of the Agriculture Sciences University of Mohaghegh Ardabili. Experiment treatments included different salicylic acid concentrations $(0$, $1,2 \mathrm{mM})$ and water deficit stresses $(25 \%, 45 \%, 65 \%$ and $85 \%$ Field capacity).

Result: According to results, emergence index (emergence percentage and emergence rate, uniformity emergence, and times to 10,50 , and $90 \%$ emergence) was influenced at $1 \%$ by water deficit stress. The effect of salicylic acid was significant on the emergence index. The interactions of water deficit stress and salicylic acid were effective at $1 \%$ on emergence uniformity and time to $90 \%$ emergence. Changes in plant height and heading rate were lower under water deficit stress. Also, both slope (b) and maximum content (a) decreased by water stress $(22 \%$ and $7 \%$ ). Priming by salicylic acid at $2 \mathrm{mM}$ had the highest effect on both traits and resulted in a decrease in their slopes (17\% and 13\%) and an increase in their maximum content (34 and 10\%). Plant dry weight was influenced by the interactions of water deficit stress and salicylic acid at $5 \%$ level. The plant's final height and grain weight was influenced by water deficit stress and salicylic acid. The highest grain weight was obtained at $80 \%$ and $60 \%$ field capacity with means of 0.79 and $0.75 \mathrm{~g}$, which had no significant differences with eachother. The heights grain weight $(0.72 \mathrm{~g})$ was obtained by application of 2 $\mathrm{mM}$ salicylic acid which led to an increase of $250 \%$ compared to control.

Conclusions: Overall, we showed that water deficit stress resulted in decreased emergence rate and emergence percentage of wheat and finally declined plant growth and grain weight. Application of salicylic acid in seed priming resulted in improvement in the emergence index, growth, and grain weight of wheat. Also, the highest grain weight was observed at $2 \mathrm{mM}$ concentration and it can be considered as the enhancing treatment.

\section{Keyword: Drought stress, Emergency rate, Regression model, PGRs, Wheat}

\section{Highlights:}

1- Response of plant growth stage to stress was quantified using nonlinear regression.

2- Relationship between emergence and grain weight was investigated under stress and priming by salicylic acid.

\footnotetext{
Master of Science, weed sciencse, Faculty Agricuture, University of Mohaghegh Ardabili, Ardabil, Iran

2 Professor and Associate Professor, Faculty Agricuture, University of Mohaghegh Ardabili, Ardabil, Iran

3 Ph.D. Faculty Agricuture, University of Mohaghegh Ardabili, Ardabil, Iran

* Corresponding author, E-mail: ghasem.parmoon@gmil.com

http://dorl.net/dor/20.1001.1.23831251.1399.7.2.3.2

DOI: $10.29252 /$ yujs.7.2.71

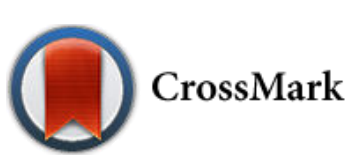

